\title{
THE
}

\section{Is the US 3PL industry overcoming paradoxes amid the pandemic?}

\author{
Muhammad Hasan Ashraf \\ University of Rhode Island, mashraf@uri.edu \\ Mehmet G. Yalcin \\ University of Rhode Island, mgyalcin@uri.edu \\ Jiayuan Zhang \\ Koray Özpolat \\ University of Rhode Island, koray@uri.edu
}

Follow this and additional works at: https://digitalcommons.uri.edu/cba_facpubs
The University of Rhode Island Faculty have made this article openly available.
Please let us know how Open Access to this research benefits you.

This is a pre-publication author manuscript of the final, published article.

Terms of Use

This article is made available under the terms and conditions applicable towards Open Access Policy Articles, as set forth in our Terms of Use.

\section{Citation/Publisher Attribution}

Ashraf, M.H., Yalcin, M.G., Zhang, J. and Ozpolat, K. (2021), "Is the US 3PL industry overcoming paradoxes amid the pandemic?", The International Journal of Logistics Management, Vol. ahead-of-print No. aheadof-print. https://doi.org/10.1108/IJLM-02-2021-0110

Available at: https://doi.org/10.1108/IJLM-02-2021-0110

This Article is brought to you for free and open access by the College of Business at DigitalCommons@URI. It has been accepted for inclusion in College of Business Faculty Publications by an authorized administrator of DigitalCommons@URI. For more information, please contact digitalcommons-group@uri.edu. 


\author{
Is the U.S. 3PL Industry overcoming paradoxes amid the pandemic? \\ Muhammad Hasan Ashraf, Mehmet G Yalcin, Jiayuan Zhang, Koray Ozpolat \\ College of Business, The University of Rhode Island, Kingston, RI
}

\begin{abstract}
Purpose: Third-party logistics (3PL) companies have experienced an explosion of volume during COVID-19. Special tiers have been introduced to provide differentiated levels of service to the customers. However, such changes in an organization reveal and intensify tensions known as paradoxes. The purpose of this research is to identify what paradoxes emerged or have become more salient specifically due to COVID-19 in 3PLs' ground operations and how they are dealt with by ground operation managers.

Design/methodology/approach: This is a qualitative study conducted in two phases. Phase one utilizes a questionnaire approach to identify the paradoxes within the 3PLs operating in the U.S. Phase two, conducted six months after phase one, follows an in-depth one-on-one interview approach. NVivo 12 is employed to analyze the interview data.
\end{abstract}

Findings: Our results show that new paradoxes did in fact emerge due to the COVID-19 and are mostly related to the performing paradox category. Findings from in-depth interviews show that the 3PL managers focus on keeping safety as priority to manage COVID-19 related paradoxes, along with modifying operational plans, improving communication, investing in training, optimizing hub network, introducing modified/new methods, and adapting modified human resource policies.

Originality: This paper is among the first known to identify paradoxes within the 3PL operations during the COVID-19 and provides insights into how these paradoxes are dealt with at mid-management level. Findings of this study provide foundations for the development of a theoretical framework on handling paradoxes within 3PLs.

Keywords: Paradox Theory, Third-Party Logistics, COVID-19, Qualitative Research 


\section{Introduction}

The novel coronavirus (or COVID-19) toppled the global supply chains as countries across the globe closed their borders (Shiraef, 2021) and companies laid off many workers (Borden et al., 2020). Demand for critical apparatus, such as Personal Protective Equipment (PPE) and ventilators, etc., surged dramatically. For example, the sale of safety glasses and masks surged up to $400 \%$ from February to June, $2020^{1}$. Moreover, there were mass protests by the healthcare workers throughout the U.S., such as in Washington DC, California, New York etc., demanding more equipment to help fight the virus (Jeffery, 2020). Long lines outside big-box stores such as Costco, etc., started to form when the residents came out to stock up on food and necessities with the fear of going into the lockdown due to the rise in the cases. In the early days of the pandemic, nonessential businesses were mandated to close, but transportation and logistics sector was deemed a "critical infrastructure industry", and hence, third-party logistics (3PLs) were required to maintain operations (Jones, 2020).

A 3PL is an external provider that operates, monitors, and provides logistics activities on behalf of a shipper (Hertz and Alfredsson, 2003; Evangelista and Sweeney, 2006). Some examples of the renowned 3PLs in the U.S. are United Parcel Service (UPS), Federal Express (FedEx) and Deutsche Post (DHL). In recent decades, the significance of 3PLs in the U.S. economy has increased multifold (Selviaridis and Spring, 2007). Armstrong and Associates estimate that U.S. 3PL market net revenues (gross revenues less purchased transportation) grew $12.1 \%$ to $\$ 86.4$ billion and overall gross revenues increased $15.8 \%$, bringing the total U.S. 3PL market to $\$ 213.5$ billion in $2018^{2}$. Recognizing the critical role of the 3PLs in the U.S. economy, Federal Emergency Management Agency (FEMA) and the coronavirus task force declared 3PLs as essential businesses and designated them as key transporters of the vital COVID packages (UPS, 2020a).

\footnotetext{
${ }^{1}$ https://www.cnbc.com/2020/04/18/healthcare-workers-protest-for-vital-protection-equipment.html

${ }^{2}$ https://www.3plogistics.com/extraordinary-growth-third-party-logistics-market-results-and-trends-for-2019including-estimates-for-190countries/\#: :text=Armstrong\%20\%26\%20Associates\%2C\%20Inc.,to\%20\%24213.5\%20billion\%20in\%202018.
} 
The demand for logistics services increased during the COVID-19 due to surge in online shopping because of lockdown rules and store closures, enforced by the U.S. government. This can be observed through Amazon finances which show the net sales for the company increasing $26 \%$ in first quarter of 2020, compared with first quarter of 2019 (Yahoo Finance, 2020). Similarly, Walmart recorded its biggest-ever growth in online sales which grew almost $97.0 \%$ in the second quarter of fiscal year 2020 compared to its first quarter ${ }^{3}$. However, the overwhelming influx of e-commerce volume and the obligation to deliver critical packages on time have placed 3PLs in a challenging position, forcing them to take desperate measures, such as suspending guaranteed delivery services or imposing shipping restrictions on large retailers (Ziobro, 2020).

Tailor-made tiers such as UPS premier and Special Operations by FedEx, have been introduced to provide differentiated levels of service for COVID packages (UPS, 2020-b; FedEx, 2020-a). Making such strategic or tactical changes in business is essential for short-term competitiveness and long-term survival (Luscher and Lewis, 2008). However, not often are these changes termed as successful (Taylor-Bianco and Schermerhorn, 2006). Employees usually resist to change and rather find comfort in past practices (Ropo and Hunt, 1995). Sudden changes such as induction of UPS premier, may trigger confusion, unease, and tensions that can obstruct, or even paralyze, decision making (Luscher and Lewis, 2008). Lewis (2000) argues that changes in an organization reveal and intensify tensions known as paradoxes, which are conflicting demands, differing viewpoints, or apparently contradictory findings. Realizing the tensions from the changes and properly dealing with them may help managers implement the strategic changes.

Paradoxes are embedded within complex organizations (Smith et al., 2010). 3PLs are extremely complex as they have not only "evolved to provide a full set of integrated logistics activities" (Zhang et al., 2015, p.31) but also seek to expand their business beyond traditional services (Chen et al., 2019). The integrated logistics activities and transition to providing full service bring unexpected tensions to 3PLs. Moreover, the emergence of COVID-19 and sudden shifts in the operations of these 3PL firms at the

\footnotetext{
${ }^{3}$ https://www.reuters.com/article/us-walmart-results/walmart-beats-on-profit-posts-record-online-sales-onpandemic-boost-idUSKCN25E1D7
} 
strategic and tactical levels have enabled the new paradoxes to emerge. According to Zhang et al. (2020), realizing the existence of paradoxes, managers can apply the paradox theory (PT) to study, embrace, and alleviate their impact. Identifying these paradoxes in operations can help 3PLs acknowledge the existence of paradoxes under stress and eventually find ways to deal with them properly. It is necessary to identify paradoxes embedded in 3PLs to develop the foundations for managers to properly handle them. Given the importance of recognizing the paradoxes, we propose and answer the following research questions:

\section{RQ1a: What paradoxes were embedded in 3PL operations before COVID-19 pandemic?}

\section{RQ1b: What paradoxes are embedded in 3PL operations during the COVID-19 pandemic?}

In addition to exploring the paradoxes that exist in 3PL operations, we also want to explore how the 3PL practitioners manage the paradoxes that specifically relate to COVID-19 pandemic. Studies have already discussed the managing of COVID-19 related situations. For example, Kumar et al. (2021) identify and analyze risk mitigation strategies for perishable food supply chains during COVID-19. Sharma et al. (2020) identify and assess the agricultural supply chains risk caused by COVID-19. El Baz and Ruel (2021) investigate the effects of disruptions impacts on supply chain resilience and robustness in COVID-19. Shahed et al. (2021) develop a mathematical model to mitigate disruptions in supply chain networks subject to natural disaster like COVID-19. Different from these studies, we focus on finding specific ways in which 3PL managers handle the paradoxes related to COVID-19 situations. Past research applying PT to logistics domain serve the purpose of identifying and understanding of paradoxical tensions but fall short of providing information or guidance on how to handle such paradoxes (Palsson and Sandberg, 2020). Filling this research gap, we aim to find approaches that 3PL practitioners apply to deal with the paradoxes and provide insights to general practitioners for handling them properly. Therefore, we seek answers to our second research question:

RQ2: What approaches are undertaken by the 3PL operations managers to manage the paradoxes which emerged amid COVID-19? 
The contribution of our study is twofold. First, we extend the PT into 3PL domain and identify what paradoxes exist in ground operations before and during the COVID-19. Second, we determine through indepth interviews with 12 3PL operations managers on how these paradoxes are managed during the COVID-19. Our findings show that new paradoxes did in fact emerge due to the disruptions caused by COVID-19 and are mostly related to one category - performing paradoxes. We also find that the most common approaches by the 3PLs to manage these paradoxes are to modify operational plans, improve the communication between the workforce, invest in training of employees, optimize the hub network, alter the human resource policies, modify or introduce new operational methods, and promote the safety culture within the hubs. The findings of this study would assist the managers of the 3PL firms in decision making by assessing the paradoxes that are present in their operations and determining how to deal with them.

\section{Theoretical Background}

Paradox is defined as contradictions embedded within a statement (e.g., Murnighan and Conlon, 1991), human emotions (e.g., Vince and Broussine, 1996) or organizational practices (e.g., Eisenhardt and Westcott, 1988). Paradox studies adopt an alternative approach to tensions, exploring how organizations can attend to competing demands simultaneously (Smith and Lewis, 2011). Choosing among competing tensions might aid short-term performance. However, a paradox perspective argues that long-term sustainability requires continuous efforts to meet multiple, divergent demands (Cameron, 1986; Lewis, 2000).

Smith and Lewis (2011) categorize the paradoxes into four types. Learning paradoxes surface as dynamic systems transform, reinstate, or modernize (O'Reilly and Tushman, 2008). Belonging paradoxes arise when individuality and homogeneity of individuals and groups are struggled for at once (Brix-Asala et al., 2018). Organizing paradoxes appear as multifaceted systems, and create competing designs and processes to achieve a preferred outcome (Lewis, 2000). Performing paradoxes surfaces from the plurality of stakeholders and result in competing strategies and goals (Smith and Lewis, 2011). In addition to these four main categories, Smith and Lewis (2011) introduced six additional categories obtained from the 
groupings of the main categories. These additional categories are learning-belonging, learning-organizing, belonging-organizing, learning-performing, performing-belonging, and performing-organizing paradoxes (Smith and Lewis, 2011). Organizational understanding and translation of these paradoxes and their influence on firm's performance are crucial (Schad et al., 2016). If they are not dealt with simultaneously, the contradictory forces among these tensions would balance out the benefits brought in by both the paradoxical elements (Gebert et al., 2010; Palsson and Sandberg 2020).

PT is still in novel stages in the supply chain domain, but it gradually is gaining popularity. For example, Maalouf and Gammelgaard (2016) identify organizational paradoxes that emerge when firms implement lean practices and presented a range of managerial responses used for dealing with the emerged paradoxes. Xiao et al. (2019) show how purchasing and sustainability managers make sense of and respond to paradoxical tensions in sustainable supply chains. van der Byl and Slawinski (2015) show the potential of PT to understand the nature of tensions in corporate sustainability and generate creative approaches to address them. Jarzabkowski et al. (2013) develop an empirically grounded process model and show how managers experience paradoxes and their approach to cope with them over time. Sandberg (2017) explores the applicability of the PT in the global sourcing context and outlines global sourcing-related paradoxes. Zhang et al., (2020) apply PT to identify the paradox elements in the literature. Palsson and Sandberg (2020) apply PT to packaging logistics and develop a conceptual framework for organizational paradoxes related to packaging systems.

According to Lieb (1992, p. 29), 3PL involves "the use of external companies to perform logistics functions that have traditionally been performed within an organization". 3PLs are performing growing roles in extended logistics operations converting their portfolio from mere movers of goods to strategic value-added entities (Jayaram and Tan, 2010). With the growing awareness of the strategic outcomes of logistics (Chang and Grimm, 2006) and the recognition of the benefits gained from leveraging the services of 3PLs (Stank et al., 2003), logistics researchers and practitioners make enhancing the 3PL performance a high priority (Griffis et al., 2007). 
Palsson and Sandberg (2020) discuss that supply chain scholars have acknowledged the notion of tradeoffs for a long time within the logistics industry. However, these trade-offs are mainly limited to tensions regarding operational performance in the physical flow of goods. Lewis (2000) says that actors tend to simplify complex reality into polarized either/or distinctions, whereas the distinctions should be taken as two sides of the same coin to achieve maximum performance. PT provides insights to supply chain researchers on how to consider these tensions, determine their types and manage them effectively (Palsson and Sandberg, 2020). As discussed by Sandberg (2017), supply chain researchers still have not used the PT to its full potential to identify and manage the tensions present in the industry. To the best of our knowledge, no research utilizing paradoxical lens in 3PL domain to identify tensions due to COVID-19 has been executed yet. Therefore, we aim to identify what paradoxes have occurred exclusively in the 3PL operations pre and during COVID-19 period. 3PLs are important because they play a significant role in the COVID19 as online shopping becomes the dominant shopping method. As 3PLs are complex organizations, PT offers a suitable lens through which to view such complexity (Palsson and Sandberg, 2020). The uncertainty and tensions caused by COVID-19 provide us a perfect setting to examine the paradoxical tensions in the 3PL operations (Ivanov, 2020).

\section{Methodology}

We designed a two-stage study where we apply qualitative survey to identify the paradoxes in 3PLs in the first stage, and in-depth one-on-one interviews in the second stage to find out the ways 3PL's handle or deal with the paradoxes identified from the first stage. Similar to Macdonald and Corsi (2013), we followed the qualitative research principles from Grounded Theory (GT) tradition of Corbin and Strauss (2008) and general case study methods from Yin (2003). GT offers a thorough approach to develop empirical theory in new research areas, or when broad literature streams are being combined (in this case 3PL, PT, and Covid-19) in new research contexts (Randall and Mello 2012).

\subsection{Qualitative survey}


The purpose of the qualitative open-ended questionnaire-based survey is to explore the paradoxes that appear during the pandemic. This open-ended survey is underpinned by a social constructionist philosophy (Giles and Yates, 2014). While our study did not have a pre-determined number of respondents, we kept adding participants based on the interplay among new insights and findings from open-ended questionnairebased survey responses, literature, and theoretical manifestations (Nilsson, 2019; Glaser and Strauss, 1967). In total, the survey data is gathered from 12 respondents working in the U.S. 3PL industry.

We implemented a convenience-sampling approach for selecting interviewees (Flick, 2007). Most of the respondents were approached through personal contacts who worked at the major U.S. 3PLs, which have a combined revenue of approximately $\$ 439$ bn in 2019. In cases where we were not able to find relevant personnel, we adopted a snowball approach and asked the initial interviewees to facilitate contact with another manager/supervisor, whom they believe could provide further insights on our topic of interest. All the participants were of mid-management level and worked either at a major consolidation/distribution center or were involved in operations through corporate offices. Appendix I presents the job description and titles of each respondent. The reason we selected these participants is because they have relevant knowledge on the tensions within the 3PL ground operations and can give credible insights regarding the tensions embedded in the 3PL ground operations pre-post COVID-19. Selecting mid-management level participants has been justified in previous studies (Balogun and Johnson, 2004; Huy, 2002).

The interview questions were developed after a thorough brainstorming session amongst the authors. The developed questionnaire was checked for clarity by two supply chain researchers who have sufficient research on 3PLs and PT. The questionnaire was finalized after several rounds of revisions. The modified version was pretested by a manager of one of the 3PL firms (not included in the participant list) to assess the structure, length, and appropriateness of the questions used. The final version was designed on Qualtrics and consisted of an explanation on paradoxes followed by open-ended questions. Participants were encouraged to reach out to the authors in case they do not understand the concept of paradox. If they decided to proceed, they were asked to think about the paradoxes that they experienced in their day-to-day 
operations before COVID-19 and the paradoxes that occurred specifically due to the COVID-19. Appendix II provides the protocol for qualitative survey.

We distributed the survey to the respondents individually. Paradoxical patterns started to form right away with the second respondent and the final list of paradoxical categories emerged after the eighth respondent. Following Kaufmann and Denk (2011) suggestion, we collected responses from four more respondents to enrich the understanding and to elaborate on the emergent themes found. Each incremental qualitative survey response provided no additional information (Kaufmann and Denk, 2011). There are previous qualitative studies that reached theoretical saturation with similar size of respondents (Nilsson, 2019; Murfield and Tate, 2017; Macdonald and Corsi, 2013).

\subsubsection{Analyzing the Responses}

We applied within and cross case analysis to analyze the responses. We analyzed the illustrative quotations with a recommended two-stage process of analysis (Gioia et al., 2013; Pratt et al., 2006). We first extracted the keywords from each response. We coded these keywords to identify the paradoxes the participants mentioned. We then coded the paradoxes using the paradoxical framework from Smith and Lewis (2011) and classified these paradoxes into performing, learning, organizing, belonging, learning-belonging, learning-organizing, belonging-organizing, learning-performing, performing-belonging, and performingorganizing paradoxes. The authors conducted several rounds of discussion on the disagreements among the coding until an agreement was reached.

\subsubsection{Results}

Table I shows paradoxes based on our qualitative data that are embedded in day-to-day operations compared to specific ones that arose due to the COVID-19. Table II shows the first order and second order coding of the data for daily operations paradoxes with illustrative excerpts from the study respondents.

[Insert Table I here]

[Insert Table II here] 
Our results show that performing paradox is the most prominent paradox experienced by the 3PLs during the COVID-19. Maintaining the adequate distance amongst employees but also sustaining high serviceability of the packages is of great concern for the 3PLs. Moreover, employees calling off due to sickness while the hub is filled with package volume also hinders the performance for the 3PLs. This type of paradox stems from the plurality of stakeholders and result in competing strategies and goals (Smith and Lewis, 2011). One of the participants stated:

"Maintaining social distancing while hiring more employees to work in an area.

Spending money on PPE while also trying to save money from lost time due to COVID."

Additionally, learning paradox is another major category that emerged. Due to the strategic and tactical shifts in the operations, the 3PL employees are forced to learn newer technologies and procedures that they have not performed before. 3PL firms are known as "old school" and the conventional 3PL players such as UPS are still stuck in $20^{\text {th }}$ century where the employees are resistant to change (Ziobro, 2018). To make matters worse, most of the conventional 3PLs are unionized (e.g. Teamsters at UPS) which prevent the corporate to freely induce change in organization. One of the participants stated:

"Now that people are working from home every single day, the enjoyment of working from home is not as great."

Another paradox that emerged during the COVID-19 is the paradox of organizing which arises when conflicts between qualities such as commitment, trust, and creativity on one hand, and efficiency, discipline, and order on the other side emerge (Lewis, 2000). Our findings reveal that the hub managers experience this tension especially when they have to maintain the control and flexibility simultaneously. Also, managers are facing the dilemma to hire more people on regular basis to process the increased volume while maintaining safety by letting minimum employees inside the hub. For instance, a participant responded:

"Holding the workforce accountable for attendance but allowing room for extenuating circumstances due to the pandemic."

Further we observed that extended paradox categories i.e., Performing-Belonging, PerformingOrganizing and Learning-Organizing also emerged during COVID-19 that were not experienced, or given 
attention to, by the 3PL managers before. Table III presents the first and second order coding for the paradoxes emerging during COVID-19 along with the supporting excerpts from the study participants.

\section{[Insert Table III here]}

The next step of our study is to investigate how these paradoxes are managed by the 3PL managers.

\subsection{Interviews}

The purpose of the interview approach is to gain deep insights into the complex phenomenon of PT and how it is addressed by the 3PL managers. Based on the findings from the qualitative survey, an interview protocol was developed comprising semi-structured questions. The interview protocol was revised based on the inputs from the co-authors. Also, it was checked for clarity by 3PL supervisors who were not part of the main study. We then revised the interview protocol after integrating the feedback. The final interview protocol included questions on fifteen paradoxes (see appendix III), with each paradox being asked with a semi-structured question. Considering the novelty of the PT in the field, interview approach is the most appropriate method to determine how the paradoxes are managed in the COVID-19 context. Moreover, we conducted interviews six months after the first study was carried out. The reason for this was to wait and let the 3PL managers determine the most optimum approaches to manage these paradoxes and to see if their perceptions about the initial paradoxes have changed or not. As COVID-19 is a new phenomenon, considering the time factor is important as organizations take time to move from identifying to conceptualizing and to managing the changing phases (Beatty and Ulrich, 1991).

Study participants in the qualitative survey (Phase 1) were reached out again and they agreed to be part of the in-depth interviews. One-on-one in-depth interviews were conducted over the Zoom virtual meeting platform with participants. Although there is no set rule for the number of interview participants needed to reach saturations, past research has shown that 6-8 samples are generally enough for a homogenous sample, while 12-20 are adequate for heterogeneous samples (Carter and Jennings, 2004). While the content of each interview was distinctive (building, operational role, experience etc.), the first common patterns emerged 
after the sixth interview and hence gave an indication of a theoretical saturation point. Six more interviews helped to enrich the understanding and to elaborate on the emergent themes discovered. We echo Nilsson (2019) argument that due to the subjective nature of the interview process; it was difficult to determine when the actual saturation point occurred. However, the 12 interviews conducted provided thorough representation to obtain in-depth insights on how the 3PL managers approach paradoxes within the 3PL operations.

All the participants had the prior knowledge of paradoxes due to the questionnaire exercise they went through from the qualitative survey but were given a refresher on the research context. Participants were explicitly told to answer their management approaches only in the COVID-19 context. Each participant was also instructed not to answer a question if they believe they have not experienced the paradox firsthand. The one-on-one setting allowed the participants to engage in an unrestricted manner to share their experiences in managing the paradoxes. Interviews ranged from 23 to 40 minutes and were audio recorded and transcribed.

\subsubsection{Analysis}

Our study uses Braun and Clarke's (2006) six phases of thematic analysis approach i.e. (1) familiarizing yourself with the data; (2) generating initial codes; (3) searching for themes; (4) reviewing themes; (5) defining and naming, and (6) producing the report (Braun and Clarke 2006, p.87).

NVivo 12, a commonly used qualitative software package, is employed to analyze the interview data. As this study is exploratory in nature and does not impose any pre-existing coding framework or theoretical constructs, an inductive coding approach is applied. We categorize our data into fifteen categories, where one category represents one paradox. We analyze our data based on each paradox individually and inductively designate a node (or a code) to a concept or theme found in the response of each participant for the respective paradox category. At times multiple concept nodes were also coded for a response in a transcript, indicating that a response contained multiple concepts. In doing so, we follow Tu (2018) hierarchical coding scheme in NVivo. 
Multiple steps were taken to ensure reliability and validity of our results. First, the participants were asked to review the interview transcripts themselves and provide feedback on any misunderstandings or omissions made during the transcribing process. Second, diversity of participants was ensured by selecting them from different, but major, U.S. 3PL firms. Third, two researchers took part in the coding process to examine the interview transcripts and independently develop concept nodes. At each coding level, the researchers compared and discussed the independently developed codes and through agreement merged into an agreed-upon single list of concept nodes. In total, 31 lists were formed throughout the process, 15 lists at level one (each list referring to each paradox), 15 lists at level two (each list comprising of higher order themes for each paradox) and the final list at level three (comprising the comprehensive list of themes cross coded between each paradox). The inter-rater reliability was above 0.7 for each level, which indicates substantial interrater reliability (Landis and Koch, 1977). Last, coding results were examined with the participants and reviewed among researchers to ensure the objectivity of the analysis. Appendix IV lists the analytical results of the qualitative research for the Level I and II coding.

\subsubsection{Results}

GT involves blending empirically based evolving themes through interviews against the literature (Randall and Mello, 2012). This approach allows for the content of common themes to be placed in a new theoretical structure (Charmaz, 2006). The analysis of second order codes with similar content produced seven major themes (third-order codes) and relationships that form the basis for the propositions. This highest level of a concept hierarchy can be considered as theoretical constructs (Tu, 2018). Figure 1 shows these main themes and their corresponding second-order codes. Level III codes that had less than 10 references were dropped off and not considered for the analyses.

\section{[Insert Figure 1 Here]}

Figure 2 shows a group query output developed in NVivo, showing the connections of the proposed themes to their respective paradoxes along with the number of corresponding excerpts in the transcripts. The themes that emerged through our analysis have potential implication for the supply chain management 
and PT literature, as these approaches impact the 3PL firms in their strategic and operational performance by effectively managing the embedded paradoxes. Based on the results, we developed several propositions on how 3PL operations managers cope with paradoxes during the pandemic in the following section.

\section{[Insert Figure 2 here]}

\section{Discussion and propositions development}

Our study investigates what paradoxes exist within the ground operations of the 3PLs and how these paradoxes have changed, or new ones emerged, due to the COVID-19. The follow up investigation is to see what approaches are undertaken by the 3PL managers to deal with these paradoxes during the COVID-19. Our results are in line with Maalouf and Gammelgaard (2016) that employees' involvement (safety culture, training, human resource), experimentation (modified/new methods, modified plans), facilitation of group discussions (communication), and coaching (training) are the approaches to manage paradoxes that emerge due to change in the organization. We provide discussions based on our findings and offer relevant propositions in the next section.

\subsection{Safety}

3PLs portray themselves as socially responsible and have a corporate social responsibility in following sound workplace safety measures (Piecyk and Bjorklund, 2015). Moreover, 3PLs today are still labor intensive and the performance of these firms are dependent on the health and safety of the employees (Carter and Jennings, 2004; Das et al., 2008). The effects of COVID-19 on 3PLs are unprecedented (Ketchen Jr. and Craighead, 2020), leading to increasing number of workers working within the 3PL operations falling sick (Abrams and Silver-Greenberg, 2020). Safety versus production is one of the oldest paradoxes in the management world (Hu, 2020) and has been intensified during the COVID-19 when the sudden increase in e-commerce volume had placed 3PL firms in a dilemma of balancing between revenues and safety of employees. To manage such paradoxes, 3PL managers promote a culture of safety within the 3PL operations to make sure that employees perform at their maximum potential without being exposed to the risk of COVID-19. Participant 1 mentioned: 
"So, we call it a culture of safety, .... The first thing you hear when you walk in, and the last thing you hear when you walk out are always safety "

Promoting a culture for safety that leads to a better workplace performance has been studied and is associated with improved firm performance (Hajmohammad and Vachon, 2014). All of the interview participants had a consensus that any decision made in operational context during COVID-19 is safety focused. It is pertinent to achieve both goals, i.e. revenue and safety, and for that, a safety culture enables an atmosphere for the employees to work effectively without getting sick (Hu, 2020). Relating to the past literature on managing paradoxes, and the responses from the interview participants, we see that incorporating safety in the 3PL operations is a major approach to manage paradoxes during COVID-19. Thus, we propose:

Proposition 1: Ensuring safety culture is one of the approaches to manage paradoxes in 3PLs during the COVID-19 pandemic. 3PL managers ensure that all the policies are safety centric.

\subsection{Modifying operational plans}

Modifying operational plans is a commonly used approach to cope with uncertainty in supply chains (Schutz and Tomasgard, 2011). Modifying operational plans is also termed as operational flexibility, which refers to the capability of a firm to respond to uncertainty (Yu et al., 2015). Uncertainty in 3PL operations is a hurdle to the effective management and control of operations (Sanchez-Rodrigues et al., 2010). According to Ketchen Jr and Craighead (2020), 3PL firms were not ready for the massive surge in ecommerce volume due to the lockdowns. Such uncertainty forced the 3PLs to modify their plans and search for new solutions which lead to the emergence of paradoxes (Smith et al., 2017). These paradoxes take many forms during the COVID-19 in 3PL operations, such as contradictory goals in maintaining service levels while simultaneously lowering the sickness rate. According to the participants, their typical operational plans are not applicable due to uncertainty surrounding COVID-19 and short-term plans are modified on weekly basis. Participant 12 mentioned: 
"We had to throw away our long-term operational plans"

Therefore, modifying operational plans is more important than ever to navigate uncertainties and to overcome tensions emerging in COVID-19. There are many ways to modify operational plans. For example, Sabri and Beamon (2000) define two types of modifications in operations: the first one is volume flexibility which allows for increasing the capacity of the operations such as increasing number of sorts or increasing the sort time, while keeping optimal number of workers within the hubs to safely process ever increasing volumes. The second type of modification is delivery flexibility, i.e., the ability to modify delivery operations. 3PLs modified their delivery operations by introducing interaction less delivery service ${ }^{4}$ There is a consensus in the existing literature that modifying operational plans is important to minimize the effects of external turbulence such as COVID-19 by allowing a system to respond to uncertainties (Huang et al., 2014; Sheffi and Rice 2005) and hence, overcoming the tensions raised due to it. Drawing on the existing literature and the PT, modifying operational plans is an effective approach to manage paradoxes that emerged during COVID-19. Through interviews we found that the 3PL managers are modifying the operational plans on regular basis since the start of the pandemic, thus, we propose:

Proposition 2: Modifying operations plans is one of the approaches to manage paradoxes in 3PLs during the COVID-19 pandemic. 3PL managers modify operational plans to allow for flexibility in the operations to cope up with the uncertainties associated with COVID-19.

\subsection{Communication}

Frequent communication of objectives, and major changes in operations helps keeping all stakeholders informed and focused on operational goals (Chin et al., 2004). Wyatt (2006, p.6.) stated: "Effective communication is the lifeblood of a successful organization. It reinforces the organization's vision, connects employees to the business, fosters process improvement, facilitates change, and drives business results by changing employee behavior." Organizations have traditionally focused on external communications and

\footnotetext{
${ }^{4}$ FedEx Newsroom: "FedEx Stands Up Special Operation to Help Fight COVID-19", available at:

https://newsroom.fedex.com/newsroom/fedex-stands-up-special-operation-to-help-fight-covid-19/
} 
not much on internal communication, such as communication between employee to employee (OmilionHodges and Baker, 2014). Such lack of focus was observed during the initial days of the pandemic when the employees in 3PL firms complained about not being well-communicated regarding the safety policy implemented by their firms ${ }^{5}$. Interview participants acknowledged the significance of communication and agreed that clear communication with employees was necessary to win-over their confidence in these uncertain times. Participant 6 mentioned that:

"So clear communication with the people that work with you directly was one and only proven strategy that worked for us. “

The interview results show that the 3PL employees understand that communicating with employees would reflect in morale, motivation, and performance of the employees (Rajhans, 2012). Research has shown that communication is important in managing paradoxes within an organization (Stoltzfus et al., 2011). For instance, Barge et al. (2008) found that several paradoxes that emerged due to change in operations were managed communicatively by demonstrating "connection". Similarly, Barge and Andreas (2013) talk about different approaches to embrace tensions including a dialogue approach amongst employees to identify embedded paradoxical elements. Ranjhans (2012) emphasizes on dealing with the paradox of control and coordination through proper communication between employees. Lewis (2000) recommends that managing learning paradoxes requires open communication to compel the employees to understand the implications of the paradox. The dynamics of paradox are often vicious. By providing intime information and details about the change, employees can reflect on their tensions and escape vicious cycles rather conveniently (Smith and Lewis, 2011). Supportive communications help prevent paradoxical visions being interpreted as oversimplified or impractical (Andriopoulos and Lewis, 2009). Thus, we propose:

\footnotetext{
${ }^{5}$ NBC News: https://www.nbcnews.com/health/health-news/fedex-drivers-say-they-re-not-getting-coronavirusprotections-other-n1174031
} 
Proposition 3: Communication is one of the approaches to manage paradoxes in 3PLs during the COVID-19 pandemic. 3PL managers invest in effective communication to overcome any barriers or concerns among the employees to accept change caused by COVID-19.

\section{4. $\quad$ Training}

Research has shown that training plays a vital role in modifying attitude and behavior amongst managers and employees especially when a change is implemented in the organization (Sammalisto and Brorson, 2008). Training also provides an opportunity for the firms to prepare its employees on the latest skills while also polishing the conventional skills (Rivera et al., 2016). Tam et al. (2004) discuss the impact of training in guaranteeing safe operations along with higher productivity. Luscher and Lewis (2008) mention that the employees must be aware of the changing conditions in order to acknowledge and manage such paradoxes. Sammalisto and Brorson (2008) argue that training gives such awareness to the employees and enhances their willingness to accept changes in their operations. One of the major paradoxes that companies faced is the paradox of exploration and exploitation, where firms wanted their employees to learn newer methods within hubs but also to keep older and more efficient ones. Training plays an important role to deal with such paradox. As participant 10 mentioned:

"We not only provide opportunities to reinforce the habits and training that they previously had, but also provide opportunities for new training"

3PL managers are also working hard to cross-train their employees to overcome the issue of employee absenteeism due to the health issues. The goal of cross-training is to improve knowledge of operational activities by training the team members to the roles and responsibilities of their teammates (Marks et al., 2002). Therefore, whenever the employees call-off due to COVID sickness, cross-trained workers can be shifted dynamically to where they are needed. The interview responses showed that 3PL managers realized the significance of training in enabling the workforce to overcome the paradoxes that emerged due to COVID-19, more specifically paradoxes related to exploration-exploitation, productivity-safety, and 
productivity-employee shortage. Looking into the past literature and drawing on PT and insights from the interviews, we propose:

Proposition 4: Training employees is one of the approaches to manage paradoxes in 3PLs during the COVID-19 pandemic. 3PL managers focus on training employees to follow routines and to accept modifications in the operations caused by COVID-19.

\subsection{Human Resources}

With social distancing requirements in place, 3PL managers had to implement new human resource practices that maximize efficiency and ensure employee safety (Smith, 2020a). With peak season, the organization needed more workforce to handle the volume (Harbert, 2020). However, 3PL managers could only hire enough workers inside the hub due to safety guidelines, and therefore, an approach that became increasingly common in response to volume uncertainties and staffing limitation is the use of temporary workers (Garett, 2020). A Gartner survey on COVID-19 related workplace trends states that nearly one in three companies were hiring more temporary workers to achieve greater workforce management flexibility along with ensuring safety of employees ${ }^{6}$. Hiring temporary workers (or as mentioned as utility workers) helped logistics companies deal with sudden spikes in demand while minimizing risk of employees getting sick. Participant 8 mentioned:

"We can put on what are called utility drivers or seasonal drivers. So we were able to supplement the absenteeism by putting on new employees"

Staffing plans were developed to keep the staffing cap level under consideration and hence managers and supervisors are responsible to determine the most optimized number of workers required inside the hub to manage the volume safely and effectively (Hopp et al., 2004). Nevertheless, in the case where the volume was too high to be processed in the allotted sort time with capped number of workers, 3PL managers

\footnotetext{
${ }^{6}$ Gartner (2020): https://www.gartner.com/en/newsroom/press-releases/2020-05-06-gartner-identifies-nine-trendsfor-hr-leaders-that-wi
} 
considered extending the sort time rather than increasing the staffing inside the hub. While the sorts were running longer, and the drivers had to make more stops, the 3PL firms boosted wages, perks, and benefits of the workers (Garrett, 2020), and provided incentives such as overtime, without requiring explanation from employees.

Research has shown that an effective human resource policy in organizations helps in translating paradoxes (Sandoff and Widell, 2015). External disruptions (such as COVID-19) and the paradoxes emerging due to it have led operations and human resources intimately tied to one another (Boudreau et al., 2003). Human resources play a critical role in 3PL operations and have been highly effective in foregrounding tensions embedded in the operations (Sandoff and Widell, 2015). Looking into the effectiveness of human resource related approaches during the COVID-19, and the insights provided by the interview participants to address the paradoxes through human resource policies, we propose:

Proposition 5: Flexible and lenient human resource policy is one of the approaches to manage paradoxes in 3PLs during the COVId-19 pandemic. 3PL managers streamline the Human Resource processes for the current and new employees to facilitate them in case of inconvenience or increase in volume caused by COVID-19.

\subsection{Network Optimization}

To effectively push a large volume of packages from the origin to the destination, 3PL firms use a network of hubs (McWilliams et al., 2005). 3PL hub network is made of various small and big consolidation centers and is an important facet of the 3PLs for developing a successful logistics system (Zhang et al., 2018). These hubs have a limited capacity, and the safety guidelines due to COVID-19 have made the 3PL managers strictly adhere to the guidelines issued by CDC. Since the start of the pandemic, 3PLs are operating close to maximum capacity. Most of the reported daily volumes were exceeding "peak" holiday season volumes ${ }^{7}$. In such circumstances, 3PLs do not have enough capacity to process all the volume

7

https://www.logisticsmgmt.com/article/parcel_experts_weigh_in_on_fedex_ups_so_far_throughout_the_covid_1 9_pandemi 
coming into their overly utilized hubs, specifically from large retailers such as Nike and Macy's (Ziobro, 2020). To address this paradox, 3PL managers are doing what they call as "Rolling the loads". Rolling the loads is to process the extra volume the next day. Large shippers are told that most of their capacity is already addressed for, and that any extra trailers arriving at the hubs would have to wait for a day before being processed (Ziobro, 2020). As also mentioned by participant 7:

"We just had to sit some inbound volume and then just process it the following day and the customer was aware and knew the circumstances"

However, in case when all the volume is essential and the hub is still not able to process it, the 3PL managers leverage the other underutilized hubs in the network and divert the loads to those buildings. Participant 3 mentioned:

“We can only handle this much. If we can't, if we go over this mountain, other building needs to take this more."

In regular days, 3PL managers must inform their divisional managers before diverting the loads. However, during COVID-19, 3PL managers are given the authority to do so if necessary. The volume surge that led to longer processing and delivery times is managed through network optimization or as some respondents say, "Balancing the Volume". Therefore, to address the daunting challenges of uncertainty specifically posed by the COVID-19, 3PL managers are turning to network optimization to ensure their network is as flexible and robust as possible. The pandemic is pushing 3PLs to completely reevaluate their networks (Shih, 2020). Network optimization provides a powerful approach to address the paradoxes that emerged due to volume uncertainty and capacity constraints. Thus, drawing on the literature and responses from the interviewees in the light of paradox management, we propose:

Proposition 6: Network optimization is one of the approaches to manage paradoxes in 3PLs during the COVID-19 pandemic. 3PL managers balance network volume by relying on under-utilized facilities to divert extra volumes and capping the increase in non-essential volume caused by the COVID-19. 


\subsection{Modified/new Methods}

The COVID-19 pandemic has disturbed the operational status quo in the 3PL firms (Perritt et al., 2021). As the rules for doing business during a pandemic continue to change, 3PL firms modify their already developed methods to ensure safety along with high productivity within the hubs. 3PL managers have been extremely active in determining what tasks inside the hubs can be riskier for the employees, and hence are finding ways to modify such tasks. Participant 5 mentioned:

"Modified teamwork methods to make sure that we didn't have people close together, but they were still able to help each other out."

It has taken years for the conventional firms such as UPS to come up with the most optimal methods to efficiently run the operations inside the hubs (Ziobro, 2018). However, some of these methods involve workers to operate very closely to each other. 3PL managers have modified these methods by ensuring that the social distancing remains the most important factor in operating. One of the methods changed, which was reported by almost all the participants, was to limit the number of unloaders inside the trailer. As per standard operating procedure (SOP) for most of the 3PL firms, trailers are emptied by two unloaders at the same time. However, this unloading method has been strictly prohibited and modified. 3PL managers ensure that only one unloader is unloading the trailer at a time. As participant 8 mentioned:

"We were not allowed to put two individuals in the same trailer. So you would only have single individuals unloading. ”

In addition to unloading, all the other work areas inside the hub that required teamwork by SOP, such as sorting and picking off (McWilliams et al., 2008), were also modified and individuals were positioned at least six feet apart. Participant 5 mentioned:

"Modified teamwork methods to make sure that we didn't have people close together, but they were still able to help each other out." 
Business research suggests that a firm's response to disruptions such as the COVID-19 depends greatly on its ability to have flexibility in its operational methods (Costantino et al., 2012; Gligor et al., 2013). Firms that modify their operational methods or practices tend to gain more advantage in terms of performance than those who stick to their conventional methods (Zhu and Sarkis, 2004). 3PL's ability to be flexible in modifying its methods allows it to respond to complex, global, and dynamic environments (Andriopoulos and Lewis, 2009). Similarly, Ozanne et al. (2016) argue that firm's ability to be flexible is necessary to identify, translate, and manage tensions as they emerge due to a major disruption. Kristal et al. (2010) show method flexibility as a competitive capability for a firm to adapt to changing environments. Looking into the past literature we can see the effectiveness of changing the operational methods to cope up with the uncertain conditions and to manage the paradoxes emerging due to it. Our interview responses align with the extant literature; hence we propose:

Proposition 7: Modifying or introducing new operational methods is one of the approaches to manage paradoxes in 3PLs during the COVID-19 pandemic. 3PL managers modify or introduce new conventional operations methods to adjust to unique and dynamic circumstances caused by COVID-19.

\subsection{Theoretical Implications}

The major theoretical contribution of this paper is to extend the PT in the supply chain domain and examine the paradoxes within the 3PL context during the COVID pandemic. To the best of our knowledge, our study is the first to identify the paradoxes with in 3PL ground operations and how 3PL managers manage such paradoxes during the COVID-19 pandemic. This study paves the way for future studies on paradoxes in 3PL operations and the findings provide foundations for the development of a theoretical framework on handling paradoxes. Rigorous qualitative approach can build a thorough and sound knowledge regarding the paradoxes within the 3PL context.

Our in-depth interview findings provide propositions for future studies to test our theoretical constructs. While our study is among the first to empirically apply a paradox perspective in 3PL context during COVID-19, we also contribute to the general literature on tensions and paradoxes (Schad et al., 2016). 
Researchers have advocated the use of contingency theory, institutional complexity theory and complexity theory as promising responses in attempting to overcome tensions (Zhang, et al., 2020). However, we demonstrate the value of applying PT to logistics domain to harmonize the on-ground risks with corporate goals, and to identify responses in dealing with the tensions in a complex view of organizations (Quinn and Cameron, 1988) that emerged due to COVID-19.

Extra demand for flexibility (i.e., safety, network optimizations, modified/new methods, human resource, etc.) combined with existing paradoxical tensions such as cost vis-à-vis service levels among the 3PLs operations could exacerbate existing tensions and potentially introduce new tensions/interdependencies, which may then spur anomalies through the PT lens. While Zhang et al. (2020) mention that the paradoxes with more than two paradoxical elements provide a hint to refine the PT, our findings show a possibility that PT could be extended (Kaufmann and Denk, 2011) to investigate tensions that exist or become more salient simultaneously across three or more elements.

\subsection{Managerial implications}

Our research serves to bridge the gap between theory and practice (Fischer, 2020). This research can raise awareness for practitioners regarding what paradoxes are occurring during the current crisis and how the 3PL mid-management level employees are handling them. Through the questionnaire we determined that the operations managers are facing severe paradoxes, such as paradoxes between making efficient plans to achieve high productivity while focusing on lowering down the number of workers in the hub and extending the sorts. Based on our in-depth interviews we find that managers will choose to build a culture of safety, modify operational plans, communicate with employees, provide training to employees, implement flexible and lenient human resource policies, optimize network utilization, and modify or introduce new methods to manage the paradoxes raised from the pandemic. These seven approaches show their potential on managing the paradoxes. Practitioners in other types of 3PLs can also learn from these approaches to handle the paradoxes they met. Building a safety culture ensures that the volume is effectively serviced while overcoming the issues of safety and other health risks within ground operations. Modifying 
the operational plans, which allows for increasing operation capacity while keeping optimal number of workers, is another approach to handle paradoxes in COVID-19. 3PL managers also value the role of communication with employees and the customers on addressing the paradoxes. Training plays a crucial role in preparing the employees to work on newer methods while also educating them on the importance of keeping the old methods. Cross-training is critical during the COVID-19 to have employees ready to take over the positions of the employees who call in sick. Leveraging the firm network, which includes using underutilized hubs, rebalancing the volume, and adding temporary facilities in the network, is another important approach to manage most of the paradoxes related to increased volume. 3PLs are not able to establish newer sorting facilities in such a short period of time, hence optimizing the network by balancing the volume is an effective approach. Furthermore, modifying current methods or introducing new ones enables firms to practice and be more competitive than those who stick to their conventional methods. Lastly, flexible and lenient human resource policies can help 3PL managers to deal with paradoxes related to employees. For example, incentives such as overtime, paid leaves etc. are given to the employees during COVID-19 to compensate them for their extended working hours. Based on the approaches we identified, managers can make use of these approaches to deal with paradoxes in future pandemic related situations.

Elements triggered by COVID-19 added to the existing paradoxes could be simultaneously creating unsurmountable tensions, for the managers in everyday operations. In those scenarios, managerial intuition might be coming to the rescue to help balance the tensions among (not between) three or more paradoxical elements.

\section{Conclusion and limitations}

Qualitative research provides an opportunity for us to gain fruitful insights into the theoretical development of PT within supply chain management. This study provides awareness on what paradoxes are embedded within 3PL ground operations before and during the COVID-19 era, and how they are managed during the COVID-19. We first reviewed literature and developed a qualitative questionnaire survey that was shared with the active 3PL professionals working in U.S. Based on the responses, we identified paradoxes that 
existed both before and during COVID-19 and classified them based on categories identified through literature (Smith and Lewis, 2011). Further, we developed an interview protocol based on the identified paradoxes and conducted in-depth interviews to explore what approaches are undertaken to manage the paradoxes in the ground operations during COVID-19. Seven themes pertinent to 3PL ground operations were developed through thematic analysis using NVivo 12. By providing insights on the types of paradoxes embedded within 3PL operations and how they are managed, our study represents an initial attempt to fill the void in the literature on applying PT lens within the 3PL industry. This study provides an alternative view to the popular perspective of trade-offs and argues that effectively managing paradoxes can be beneficial for the 3PL firms that aspire to build an effective logistics operation during the COVID-19.

Our research is not without limitations. First, our study is conducted in the U.S. and only includes participants from the U.S. 3PL industry. Future studies can be conducted outside the U.S. and find out whether 3PLs in other countries/continents experience different types of paradoxes, and whether their approach to manage these paradoxes is different from that used in the U.S. 3PLs. Second, although we conducted the two studies with the gap of six months, it still is a cross-sectional study as most of the indepth interviews were conducted within a short span. We recommend conducting this study at various intervals to see how the paradoxes have differed during these periods and what steps have been taken by the 3PL firms to manage them. Third, the context of this study is the conventional 3PL ground operations that take place in the already established 3PL hubs. We do not incorporate the special operations in our analysis. For instance, COVID-19 vaccine operations involve special freezer farms and have different operational SOPs. Future studies can consider the COVID-19 3PL operations and see how the paradoxes differ in that context and how are they managed. Future research can also be conducted with diverse samples representing operations that are impacted by COVID-19 in various other industries. Last, a potential future study could investigate whether three or more paradoxical tensions can exist in 3PL operations. Following an abductive approach (Sætre and Van de Ven 2021), qualitative studies with exploratory nature such as case studies/Delphi studies, focus groups, ethnography, etc., could be employed to identify such paradoxes and explain how those paradoxes are managed in operations. 


\section{ACKNOWLEDGEMENT}

We gratefully acknowledge the feedback and support provided by Dr. Martin Dresner and Dr. Rabia Hos for this research.

\section{[Insert APPENDIX I here]}

[Insert APPENDIX II here]

[Insert APPENDIX III here]

[Insert APPENDIX IV here]

\section{REFERENCES}

Abrams, R., and Silver-Greenberg, J. (2020), "Terrified' Package Delivery Employees Are Going to Work Sick", New York Times, 21 March. Available at https://www.nytimes.com/2020/03/21/business/coronavirus-ups-fedex-xpo-workers.html (accessed on 1 Jan 2021)

Andriopoulos, C., and Lewis, M. W. (2009), "Exploitation- exploration tensions and organizational ambidexterity: managing paradoxes of innovation”, Organization Science, Vol. 20 No. 4, pp. 696-717.

Balogun, J., and Johnson, G. (2004), "Organizational restructuring and middle manager sensemaking", The Academy of Management Journal, Vol. 47 No. 4, pp. 523-549.

Barge, J.K., Lee, M., Maddux, K., Nabring, R. and Townsend, B. (2008), "Managing dualities in planned change initiatives", Journal of Applied Communication Research, Vol. 36 No. 4, pp. 364-90.

Barge, K., and Andreas, D. (2013). Communities, conflict, and the design of dialogic con-versation. In J. Oetzel and S. Ting-Toomey (Eds.), The SAGE handbook of conflict communication: Integrating theory, research, and practice (2nd ed., pp. 609-634). Thousand Oaks, CA: Sage

Beatty, R. W., and Ulrich, D. O. (1991),'Re-energizing the mature organization”, Organizational Dynamics, Vol. 20 No. 1, pp. 16-30.

Borden, T., Akhtar, A., Hadden, J., and Bose, D. (2020), “The coronavirus outbreak has triggered unprecedented mass layoffs and furloughs. Here are the major companies that have announced thay are downsizing their workforces", available at: https://www.businessinsider.com/coronavirus-layoffsfurloughs-hospitality-service-travel-unemployment-2020 (accessed on 26 April 2021) 
Boudreau, J., Hopp, W., McClain., J. O., and Thomas., L. J. (2003), "On the interface between operations and human resources management", Manufacturing and Service Operations Management, Vol 5 No. 3 , pp. 179-202.

Braun, V and Clarke, V. (2006), "Using thematic analysis in psychology", Qualitative Research in Psychology, Vol 3 No.2, pp. 77-101.

Brix-Asala, C., Geisbüsch, A., Sauer, P. C., Schöpflin, P., and Zehendner, A. (2018), "Sustainability tensions in supply chains: a case study of paradoxes and their management", Sustainability, Vol. 10 No. 2, p. 424.

Cameron, K. S. (1986),'Effectiveness as paradox: consensus and conflict in conceptions of organizational effectiveness", Management Science, Vol 32 No. 5, pp. 539-553.

Carter, C.R. and Jennings, M.M. (2004), "The role of purchasing in corporate social responsibility: a structural equation analysis", Journal of Business Logistics, Vol. 25 No. 1, pp. 145-186.

Chang, L. C., and Grimm, C. M. (2006), "The application of empirical strategic management research to supply chain management", Journal of Business Logistics, Vol 27 No. 1, pp. 1-56.

Charmaz, K. (2006), Constructing Grounded Theory: A Practical Guide Through Qualitative Analysis, SAGE, Thousand Oaks, CA.

Chen, X., Cai, G., and Song, J. S. (2019), "The cash flow advantages of 3PLs as supply chain orchestrators", Manufacturing and Service Operations Management, Vol. 21 No. 2, pp. 435-451.

Chin, K-S., Tummala, V.M.R., Leung, J. P. F., and Tang, X. (2004), "A study on supply chain management practices: the Hong Kong manufacturing perspective", International Journal of Physical Distribution and Logistics Management, Vol 34 No. 6, pp. 505-524.

Corbin, J., and Strauss, A. (2008), Basics of qualitative research: Techniques and procedures for developing grounded theory, $3 r d$ ed, Sage, Thousand Oaks, CA.

Costantino, N., Dotoli, M., Falagario, M., Fanti, M.P., and Mangini, A.M. (2012),“A model for supply management of agile manufacturing supply chains", International Journal of Production Economics, Vol. 135 No. 1, pp. 451-457.

Das, A., M. Pagell, M. Behm, and A. Veltri. (2008), "Towards a Theory of the Linkages between Safety and Quality”, Journal of Operations Management, Vol. 26 No. 4, pp. 521-535.

Eisenhardt, K. M., and Westcott, B. J. (1988), "Paradoxical demands and the creation of excellence: the case of just- in-time manufacturing. In R. E. Quinn and K. S. Cameron (Eds.)", Paradox and transformation: Toward a theory of change in organization and management: pp. 169-194. Cambridge, MA: Ballinger.

El Baz, J., and Ruel, S. (2021), "Can supply chain risk management practices mitigate the disruption impacts on supply chains' resilience and robustness? Evidence from an empirical survey in a COVID-19 outbreak era", International Journal of Production Economics, Vol. 233, 107972.

Evangelista, P. and Sweeney, E. (2006), "Technology usage in the supply chain: the case of small 3PLs", The International Journal of Logistics Management, Vol. 17, No. 1, pp.55-74 
FedEx (2020-a), "FedEx Stands Up Special Operation to Help Fight COVID-19", available at: https://newsroom.fedex.com/newsroom/fedex-stands-up-special-operation-to-help-fight-covid-19/ (accessed on 23 March 2020)

Fisher, G. (2020), "Why every business professor should write practitioner-focused articles", Business Horizons, Vol 63 No. 4, pp. 417-419.

Flick, U. (2007), Designing qualitative research, Sage, London, England.

Garrett., K. (2020), " How COVID-19 Is Redefining the Logistics Workforce", available at: https://www.supplychainbrain.com/blogs/1-think-tank/post/32162-temp-to-perm-how-covid-19-isredefining-the-logistics-workforce (accessed on $10^{\text {th }}$ February 2021).

Gebert, D., Boerner, S. and Kearney, E. (2010),"Fostering team innovation: why is it important to combine opposing action strategies?”, Organization Science, Vol. 21 No. 3, pp. 593-608.

Giles, D., and Yates, R. (2014), "Enabling educational leaders: Qualitatively surveying an organization's culture", International Journal of Organizational Analysis, Vol. 22 No. 1, pp. 94-106.

Gioia, D. A., Corley, K. G., and Hamilton, A. L. (2013), "Seeking qualitative rigor in inductive research: Notes on the Gioia methodology", Organizational research methods, Vol. 16 No. 1, pp. 15-31.

Glaser, B., and Strauss, A. (1967), "Grounded theory: the discovery of grounded theory", Sociology, pp. $101-115$

Gligor, D.M., Holcomb, M.C. and Stank, T.P. (2013), "A multidisciplinary approach to supply chain agility: conceptualization and scale development", Journal of Business Logistics, Vol 34 No. 2, pp. 94108.

Griffis, S.E., Goldsby, T.J., Cooper, M. and Closs, D.J. (2007), "Aligning logistics performance measures to the information needs of the firm", Journal of Business Logistics, Vol. 28 No. 2, pp. 35-56.

Hajmohammad, S., and Vachon, S. (2014), "Safety Culture: a catalyst for sustainable development", Journal of Business Ethics, Vol. 123 No. 2, pp. 263-281.

Harbert, T. (2020), " Workforce Planning in the Age of COVID-19", available at: https://www.shrm.org/hr-today/news/hr-magazine/winter2020/pages/workforce-planning-in-the-age-ofcovid.aspx (accessed on $4^{\text {th }}$ February 2021).

Hertz, S., and Alfredsson, M. (2003), "Strategic development of third-party logistics providers", Industrial Marketing Management, Vol 32 No. 2, pp. 139-149.

Hopp, W.J., Tekin, E. and Van Oyen, M.P. (2004), "Benefits of skill chaining in production lines with cross-trained workers", Management Science, Vol. 50 No. 1, pp. 83-98.

Hu, X., Casey, T., and Griffin, M. (2020), "You can have your cake and eat it too: embracing paradox of safety as source of progress in safety science", Safety Science, Vol. 130, 104824.

Huy, Q. N. (2002), "Emotional balancing of organizational continuity and radical change: the contribution of middle managers", Administrative Science Quarterly, Vol. 47 No. 1, pp. 31-69. 
Ivanov, D. (2020), "Predicting the impacts of epidemic out-breaks on global supply chains: A simulationbased ana-lysis on the coronavirus outbreak (COVID-19/SARS-CoV-2) case", Transportation Research Part E: Logistics and Transportation Review, Vol. 136, 101922

Jarzabkowski, P., Lê, J. K. and Van de Ven, A. H. (2013) "Responding to competing strategic demands: how organizing, belonging, and performing paradoxes coevolve", Strategic Organization, Vol 11 No. 3, pp. 245-280.

Jayaram, J., and Tan, K. C. (2010), "Supply chain integration with third-party logistics providers", International Journal of Production Economics, Vol. 125 No. 2, pp. 262-271.

Jeffery, A. (2020), "Healthcare workers protest for vital protection equipment", available at https://www.cnbc.com/2020/04/18/healthcare-workers-protest-for-vital-protection-equipment.html (accessed on 30 April 2020)

Jones, J. (2020), "6 ways a 3PL can help mitigate risk in the wake of COVID-19", available at https://multichannelmerchant.com/blog/6-ways-3pl-help-mitigate-risk-in-the-wake-of-covid-19/ (accessed 11 May 2021)

Kaufmann, L. and Denk, N. (2011), "How to demonstrate rigor when presenting grounded theory research in the supply chain management literature", Journal of Supply Chain Management, Vol. 47 No. 4, pp. 6472.

Ketchen Jr, D. J., and Craighead, C. W. (2020), "Research at the intersection of entrepreneurship, supply chain management, and strategic management: opportunities highlighted by COVID-19", Journal of Management, Vol. 46 No. 8, pp. 1330-1341

Kristal, M. M., Huang, X., and Roth, A.V. (2010), " The effect of an ambidextrous supply chain strategy on combinative competitive capabilities and business performance", Journal of Operations Management, Vol 28 No. 5, pp. 415-429.

Kumar, A., Mangla, S. K., Kumar, P., and Song, M. (2021), "Mitigate risks in perishable food supply chains: learning from COVID-19", Technological Forecasting and Social Change, Vol. 166, 120643.

Landis, J. R., and Koch, G. G. (1977), "The measurement of observer agreement for categorical data", Biometrics, Vol. 33 No. 1, pp. 159-174.

Lewis, M. W. (2000)," Exploring paradox: toward a more comprehensive guide", Academy of Management Review, Vol. 25 No. 4, pp. 760-777.

Lieb, R. C. (1992), "The use of third-party logistics services by large American Manufacturers", Journal of Business Logistics, Vol. 13 No. 2, pp. 29-42.

Luscher, L., and Lewis, M. (2008), "Organizational change and managerial sensemaking: working through paradox", Academy of Management Journal, Vol. 51 No. 2, 221-240.

Maalouf, M. and Gammelgaard, B. (2016), "Managing paradoxical tensions during the implementation of lean capabilities for improvement", International Journal of Operations and Production Management, Vol. 36 No. 6, pp. 687-709.

Macdonald, J. R., and Corsi, T. M. (2013), "Supply chain disruption management: severe events, recovery, and performance", Journal of Business Logistics, Vol. 34 No. 4, pp. 270-288. 
Marks, M. A., Sabella, M. J., Burke, C. S., and Zaccaro, S. J. (2002), "The impact of cross-training on team effectiveness", Journal of Applied Psychology, Vol. 87 No. 1, pp. 3-13.

McWilliams, D., Stanfield, P. and Geiger, C. (2005), "The parcel hub scheduling problem: a simulationbased approach", Computer and Industrial Engineering, Vol. 49 No. 3, pp. 393-412.

McWilliams, D., Stanfield, P. and Geiger, C. (2008), "Minimizing the completion time of the transfer operations in a central parcel consolidation terminal with unequal-batch-size inbound trailers", Computers and Industrial Engineering, Vol. 54 No. 4, pp. 709-720.

Huang, M-C., Yen, G-F., and Liu, T-Z. (2014), "Reexamining supply chain integration and the supplier's performance relationships under uncertainty", Supply Chain Management, Vol. 19 No. 1, pp. 64-78.

Murfield, M.L. and Tate, W.L. (2017), "Buyer and supplier perspectives on environmental initiatives: potential implications for supply chain relationships", The International Journal of Logistics Management, Vol. 28 No. 4, pp. 1319-1350.

Murnighan, J. K., and Conlon, D. E. (1991), “The dynamics of intense work groups: a study of British string quartets”, Administrative Science Quarterly, Vol. 36 No. 2, pp. 165-186.

Nilsson, F.R. (2019), "A complexity perspective on logistics management: Rethinking assumptions for the sustainability era", The International Journal of Logistics Management, Vol. 30 No. 3, pp. 681-698.

Omilion-Hodges, L. M., and Baker, C. R., (2014), "Everyday talk and convincing conversations: utilizing strategic internal communication", Business Horizons, Vol.57 No. 3, pp. 435-445.

O'Reilly, C. A., and Tushman, M. L. (2008), "Ambidexterity as a dynamic capability: resolving the innovator's dilemma", Research in Organizational Behavior, Vol. 28, pp. 185-206.

Ozanne, L., Phipps, M., Weaver, T., Carrington, M., Luchs, M., Catlin, J., Gupta, S., Santos, N., Scott, K., and Williams, J. (2016), "Managing the tensions at the intersection of the triple bottom line", Journal of Public Policy and Marketing, Vol 35 No. 2, pp. 249-261.

Pålsson, H. and Sandberg, E. (2020), "Paradoxes in supply chains: a conceptual framework for packed products", The International Journal of Logistics Management, Vol. 31 No. 3, pp. 423-442.

Perritt, G., Ray, E., and Vitasek, K. (2021), " The 3PL industry: time to reset", available at: https://www.dcvelocity.com/articles/49598-the-3pl-industry-time-to-reset (accessed on $4^{\text {th }}$ March 2021).

Piecyk, M. I. and Björklund, M. (2015), "Logistics service providers and corporate social responsibility: sustainability reporting in the logistics industry", International Journal of Physical Distribution and Logistics Management, Vol. 45 No. 5, pp. 459-485.

Pratt, M. G., Rockmann, K. W., and Kaufmann, J. B. (2006). Constructing professional identity: the role of work and identity learning cycles in the customization of identity among medical residents. Academy of management journal, Vol. 49 No. 2, pp. 235-262

Quinn, R. E., and Cameron, K. S. (Eds.). (1988). "Ballinger series on innovation and organizational change. Paradox and transformation: Toward a theory of change in organization and management", Ballinger Publishing Co/Harper \& Row Publishers, Cambridge, MA.

Rajhans, K. (2012), "Effective organizational communication: a key to employee motivation and performance", Interscience Management Review, Vol. 2 No.2, pp. 81-85. 
Randall, W.S., and Mello, J.E. (2012), “Grounded Theory: An Inductive Method for Supply Chain Research", International Journal of Physical Distribution and Logistics Management, Vol 42 No. 8/9, pp. 863-880.

Rivera, L., Sheffi, Y. and Knoppen, D. (2016), "Logistics clusters: the impact of further agglomeration, training and firm size on collaboration and value-added services", International Journal of Production Economics, Vol.179, Pages 285-294.

Ropo, A., and J. G. Hunt. (1995), "Entrepreneurial processes as virtuous and vicious spirals in a changing opportunity structure: a paradoxical perspective", Entrepreneurship Theory and Practice, Vol. 19 No 3. pp. 91-111.

Sabri, E.H. and Beamon, B.M., (2000), "A multi-objective approach to simultaneous strategic and operational planning in supply chain design", Omega, Vol. 28 No. 5, pp. 581-598.

Sætre and Van de Ven (2021), "Generating theory by abduction", Academy of Management Review, Advance online publication. doi: 10.5465/amr.2019.0233

Sammalisto, K., and Brorson, T. (2008), "Training and communication in the implementation of environmental management systems (ISO 14001): a case study at the University of Gävle, Sweden", Journal of Cleaner Production, Vol. 16 No. 3, pp. 299 - 309.

Sandberg, E. (2017), "Introducing the paradox theory in logistics and SCM research: examples from a global sourcing context”, International Journal of Logistics Research and Applications, Vol. 20 No. 5, pp. 459-474.

Sanchez-Rodrigues, V., Potter, A. and Naim, M.M. (2010), "Evaluating the causes of uncertainty in logistics operations", The International Journal of Logistics Management, Vol. 21 No. 1, pp. 45-64.

Sandoff, M., and Widell, G. (2015), "Translating as Response to Paradoxes - When Implementing HRM Strategies in Service Organisations", German Journal of Human Resource Management, Vol. 29 No. 3-4, pp. 303-321.

Schad, J., Lewis., M.W., Raisch, S. and Smith, W.k., (2016), "Paradox Research in Management Science: looking back to move forward", Academy of Management Annals, Vol. 10 No. 1, pp. 5-64.

Schütz, P., and Tomasgard, A. (2011), "The Impact of Flexibility on Operational Supply Chain Planning”, International Journal of Production Economics, Vol. 134 No. 2, pp. 300-311.

Selviaridis, K. and Spring, M. (2007), "Third party logistics: a literature review and research agenda", The International Journal of Logistics Management, Vol. 18 No. 1, pp. 125-150.

Shahed, K. S., Azeem, A., Ali, S. M., and Moktadir, M. A. (2021), "A supply chain disruption risk mitigation model to manage COVID-19 pandemic risk", Environmental Science and Pollution Research, pp. 1-16.

Sharma, R., Shishodia, A., Kamble, S., Gunasekaran, A., and Belhadi, A. (2020), "Agriculture supply chain risks and COVID-19: mitigation strategies and implications for the practitioners", International Journal of Logistics Research and Applications, 1-27.

Sheffi, Y., and Rice Jr. J. B. (2005), "A supply chain view of the resilient enterprise", Sloan Management Review, Vol. 47 No. 1, pp. 41-48. 
Shih, W. (2020), "Bringing manufacturing back to the US is easier said than done", Harvard Business Review, available at: https://hbr.org/2020/04/bringing-manufacturing-back-to-the-u-s-is-easier-said-thandone

Shiraef, M. A. (2021), "Closed borders, travel bans and halted immigration: 5 ways COVID-19 changed how-and where-people move around the world'. Available at: https://theconversation.com/closed-borderstravel-bans-and-halted-immigration-5-ways-covid-19-changed-how-and-where-people-move-around-theworld-157040 (Accessed on 26 April 2021)

Smith, L. (2020a), "Tips for HR in the Supply Chain and Logistics Industries Post-COVID", available at: https://hrdailyadvisor.blr.com/2020/09/02/tips-for-hr-in-the-supply-chain-and-logistics-industries-postcovid/ (accessed on $4^{\text {th }}$ February 2021)

Smith, W. K., and Lewis, M. W. (2011), "Toward a theory of paradox: a dynamic equilibrium model of organizing", Academy of Management Review, Vol. 36 No. 2, pp. 381-403.

Smith, W. K., Binns, A., and Tushman, M. L. (2010), “Complex business models: managing strategic paradoxes simultaneously”, Long Range Planning, Vol. 43 No. 2, pp. 448-461.

Smith, W. K., Erez, M., Jarvenpaa, S., Lewis, M. W. and Tracey, P. (2017), "Adding complexity to theories of paradox, tensions and dualities of innovation and change: introduction to Organization Studies special issue on paradox, tension, and dualities of innovation and change", Organization Studies, Vol. 38 No. 3-4, pp. 303-317.

Stank, T.P., Goldsby, T.J., Vickery, S.K., and Savitskie, K. (2003), "Logistics service performance: estimating its influence on market share", Journal of Business Logistics, Vol. 24 No.1, pp. 27-55.

Stoltzfus, K., Stohl, C., and Seibold, D. R. (2011), "Managing organizational change: paradoxical problems, solutions, and consequences", Journal of Organizational Change Management, Vol. 24 No. 3, pp. 349-367.

Tam CM, Zeng S.X, and Deng Z. M.(2004). "Identifying elements of poor construction safety management in China", Safety Science, Vol. 42 No.7, pp. 569-586.

Taylor-Bianco, A., and Schermerhorn. J. (2006), "Self-regulation, strategic leadership, and paradox in organizational change", Journal of Organizational Change Management, Vol. 19 No.4, pp. 457-470.

Tu, M. (2018), "An exploratory study of Internet of Things (IoT) adoption intention in logistics and supply chain management: a mixed research approach", The International Journal of Logistics Management, Vol. 29 No. 1, pp. 131-151.

UPS (2020-a), "UPS Mobilizes Against Coronavirus in Collaboration with Global Customers and U.S. Agencies". available at:

https://pressroom.ups.com/pressroom/ContentDetailsViewer.page?ConceptType=PressReleases\&id= 1585536572387-140 (accessed on 20 April 2020)

UPS (2020-b), “UPS Healthcare Announces UPS® Premier”, available at:

https://www.globenewswire.com/news-release/2020/05/28/2040252/0/en/UPS-Healthcare-AnnouncesUPS-Premier.html (accessed on 20 June 2020)

van der Byl, A. and Slawinski, N. (2015), "Embracing tensions in corporate sustainability: a review of research from win-wins and trade-offs to paradoxes and beyond", Organization and Environment, Vol. 28 No. 1, pp. 54-79. 
Vince, R., and Broussine, M. (1996), "Paradox, defense, and attachment: accessing and working with emotions and relations underlying organizational change", Organization Studies, Vol. 17 No. 1, pp. 1-21.

Wyatt, W. (2006), "Effective communication: leading indicator of financial performance", White Paper, Watson Wyatt Worldwide, Arlington.

Xiao, C., Wilhelm, M., van der Vaart, T. and van Donk, D.P. (2019), "Inside the buying firm: exploring responses to paradoxical tensions in sustainable supply chain management", Journal of Supply Chain Management, Vol. 55 No. 1, pp. 3-20.

Yahoo Finance (2020), Amazon.com Announces First Quarter Results, available at https://finance.yahoo.com/news/amazon-com-announces-first-quarter-200100388.html (accessed on 20 Dec 2020)

Yin, R.K. (2003), Case Study Research: Design and Methods, Sage, Newbury Park, CA.

Yu, K., Cadeaux, J., and Luo, B. N. (2015), "Operational flexibility: review and meta-analysis", International Journal of Production Economics, Vol. 169, pp.190-202.

Zhang, D., Q. Zhan, Y. Chen, and S. Li. (2018), "Joint Optimization of Logistics Infrastructure Investments and Subsidies in a Regional Logistics Network with CO2 Emission Reduction Targets”, Transportation Research Part D: Transport and Environment, Vol. 60, pp. 174-190.

Zhang, J., Nault, B. R., and Tu, Y. (2015). A dynamic pricing strategy for a 3PL provider with heterogeneous customers. International Journal of Production Economics, 169, 31-43.

Zhang, J., Yalcin, M. G., and Hales, D. N. (2020), "Elements of paradoxes in supply chain management literature: a systematic literature review.", International Journal of Production Economics, Vol. 232, 107928.

Zhu, Q. and Sarkis, J. (2004), "Relationships between operational practices and performance among early adopters of green supply chain management practices in Chinese manufacturing enterprises", Journal of Operations Management, Vol 22 No. 3, pp. 265-289.

Ziobro, P (2018a), UPS's \$20 Billion Problem: Operations Stuck in the 20th Century, The Wall Street Journal, 15 June. Available at https://www.wsj.com/articles/upss-20-billion-problem-operations-stuck-inthe-20th-century-1529072397 (assessed on 20 July 2020)

Ziobro, P (2020), UPS Slaps Shipping Limits on Gap, Nike to Manage E-Commerce Surge, The Wall Street Journal, 2 December. Available at https://www.wsj.com/articles/ups-slaps-shipping-limits-on-gapnike-to-manage-e-commerce-surge-11606926669 (accessed on 30 Dec 2020) 


\section{About the authors}

Muhammad Hasan Ashraf is a PhD candidate (Operations and Supply Chain Management) in the College of Business at the University of Rhode Island. Prior to joining the program, he worked as an Industrial Engineer for United Parcel Service at Washington DC/Maryland and as a procurement engineer for a fertilizers manufacturing firm in Pakistan. Hasan holds a M.S. in Supply Chain Management from University of Maryland, and a B.E. in Electrical Engineering from National University of Science and Technology. Hasan's primary interests include third-party logistics (3PL) and supply chain sustainability. To that extent, his specific research works include, but are not limited to, studying factors such as ambidexterity and digitization that enable superior firm performances, and utilizing paradox theory in operations and supply chain management domain. Muhammad Hasan Ashraf is the corresponding author and can be contacted at: mashraf@uri.edu

Dr. Mehmet G. Yalcin is an Assistant Professor of Operations and Supply Chain Management at the University of Rhode Island, College of Business. Mehmet held various engineering and managerial positions prior to joining academia where he has been recognized with research and teaching awards. He is a certified Black Belt in Lean/Six Sigma (LSS) and Logistics, Transportation and Distribution (CLTD) and teaches Operations and Supply Chain Management courses to students and practitioners. Dr. Yalcin's research focus is on the interface of sustainability and innovation with the focal point on supply chain ambidexterity (SCX).

Dr. Jiayuan Zhang is a Postdoctoral fellow at College of Business at Colorado State University, Fort Collins. He earned his Ph.D. in Operations and Supply Chain Management from the University of Rhode Island. He holds a BAin administrative management from the Shao Guan University and aMA in public policy and an MBA in management from the Stony Brook University. His primary research lies at the intersection of humanitarian supply chains and information systems.

Dr. Koray Ozpolat is an Associate Professor of Supply Chain Management at the University of Rhode Island, College of Business. He earned his Ph.D. in Logistics and Supply Chain Management from the University of Maryland, College Park and master's degree in Electrical Engineering from Colorado State University. He also holds a graduate diploma in Purchasing and Supply from the CIPS Institute in the UK. Prior to joining the academia, he worked for the United Nations as a Logistics Systems Analyst. His research interests are in humanitarian logistics, supply chain management and information systems domains. 


\section{Figures}

Figure 1: Third-order codes generated from NVivo 12 mind map

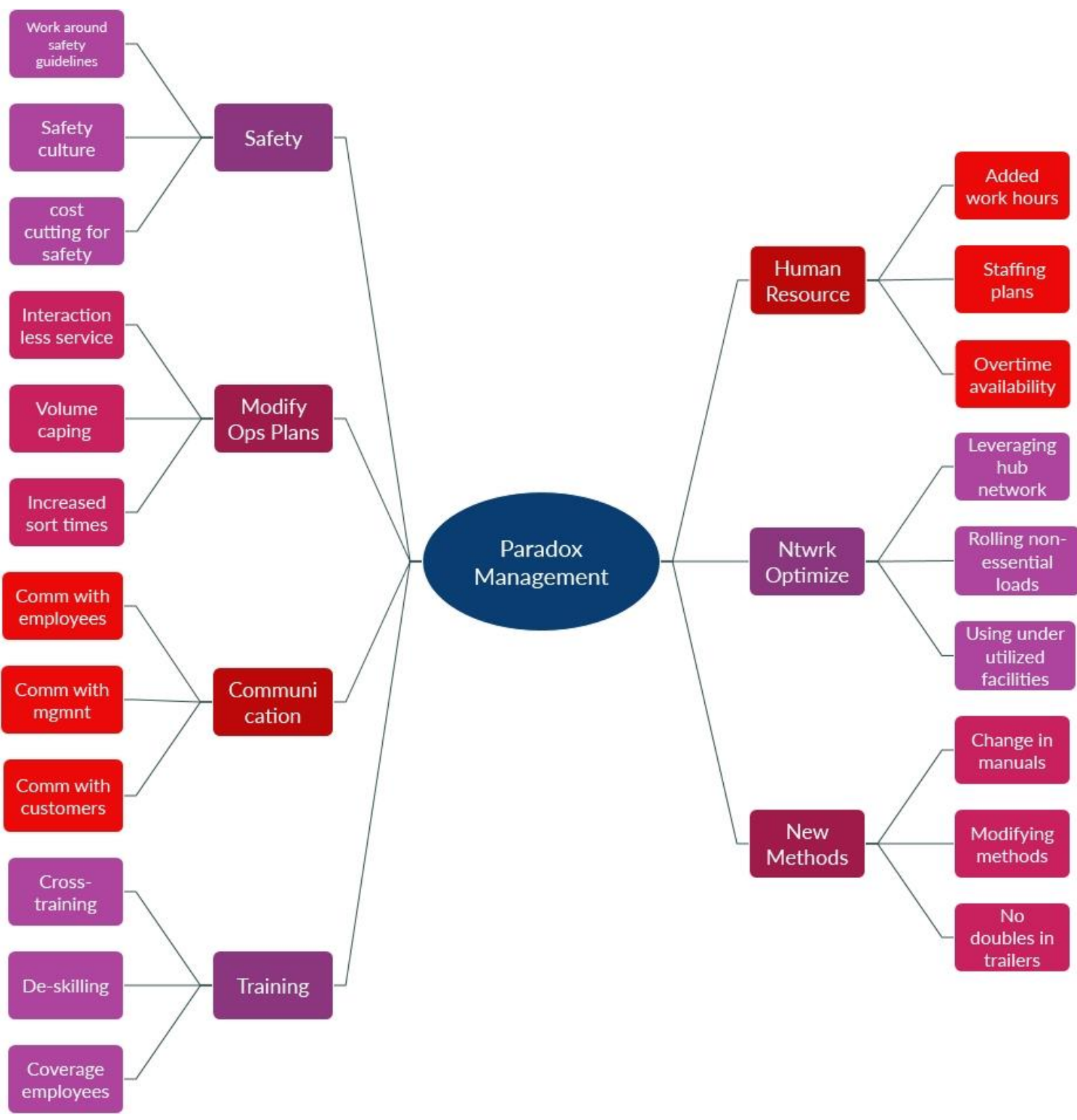


Figure 2: Group query generated in NVivo 12

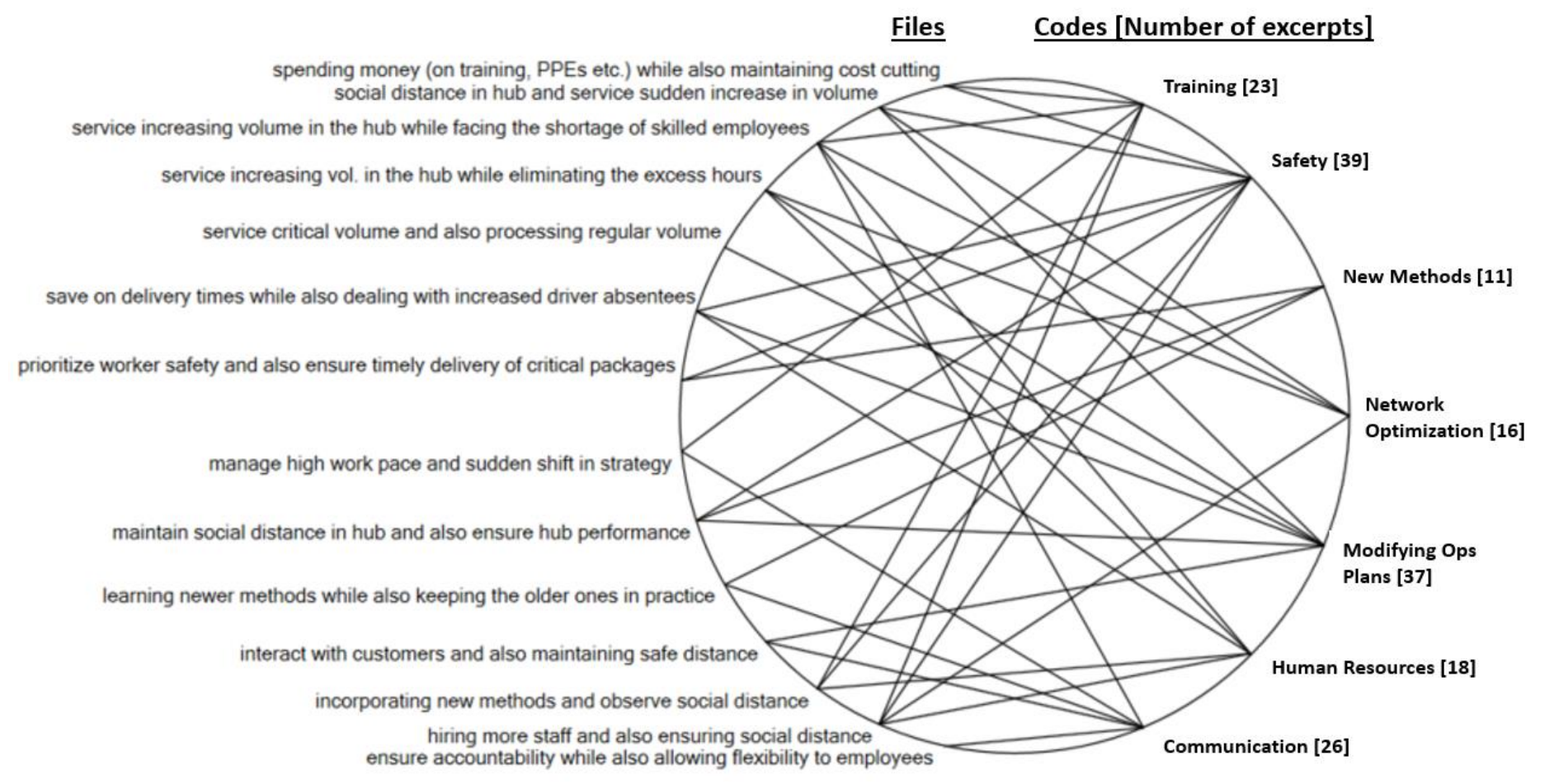




\section{APPENDIX I}

Table A-1: Mid-management respondent profiles

\begin{tabular}{|c|c|c|}
\hline \multicolumn{3}{|c|}{ Job Descriptions as per the Job Websites (UPS Jobs 2020; FedEx Jobs 2020; Ryder Jobs 2020; DHL Jobs 2020) } \\
\hline Title & $\begin{array}{c}\text { Number of } \\
\text { Participants }\end{array}$ & Job Description \\
\hline $\begin{array}{l}\text { Industrial } \\
\text { Engineer } \\
\text { Supervisors }\end{array}$ & 3 & $\begin{array}{l}\text { Develop operating plans designed to exceed the Business Plan targets. } \\
\text { Develop accurate work measurement for the most effective operating plan } \\
\text { and job setup. Provide adequate methods, planning and technical training. } \\
\text { Support operations in the implementation of new technologies, procedures, } \\
\text { and operation plans that support optimum performance and service and } \\
\text { audit for compliance. Supervise and train interns, co-ops, specialists, part- } \\
\text { time supervisors, or management trainees. }\end{array}$ \\
\hline $\begin{array}{l}\text { Operations } \\
\text { Supervisor }\end{array}$ & 2 & $\begin{array}{l}\text { Manages, plans, organizes, and directs all employees assigned to them. } \\
\text { Manages and implements security and loss prevention procedures. Prepares } \\
\text { and manages safety procedures in accordance with Company, OSHA, and } \\
\text { DOT guidelines. Prepares and implements action plans to ensure the service } \\
\text { center achieves planned productivity, load average, cube utilization, and } \\
\text { service targets. Schedules employees in accordance with hours planning, } \\
\text { the company's run bid process, and service requirements. }\end{array}$ \\
\hline $\begin{array}{l}\text { Operations } \\
\text { Manager }\end{array}$ & 5 & $\begin{array}{l}\text { Monitors purchases and evaluates driver overtime to control costs and } \\
\text { identify potential cost savings. Manages the processing of inbound and } \\
\text { outbound domestic and international shipments and ensures governmental } \\
\text { regulations and compliance requirements are met. Monitors and ensures } \\
\text { safety compliance and conducts facility and equipment safety and safety } \\
\text { compliance training. Oversees facility environmental management and } \\
\text { ensures dangerous goods and hazardous materials shipments are properly } \\
\text { handled. Interacts with labor union representatives to resolve work rules } \\
\text { issues, build strategic relationships, and resolve grievances }\end{array}$ \\
\hline $\begin{array}{l}\text { Operations } \\
\text { General } \\
\text { Manager }\end{array}$ & 2 & $\begin{array}{l}\text { Implement and manage plans to support warehousing/logistics operations. } \\
\text { Design operations layout. Improves production flow and presentation. } \\
\text { Monitors, compiles, and reports Key Performance Initiative (KPI). Leads } \\
\text { team studies related to capacity, waste, productivity, and efficiency. Ensure } \\
\text { TPS standards and adherence are maintained. Leads analysis, development } \\
\text { and implementation of new operations processes and technology. } \\
\text { Champion Continuous Improvement Process initiatives across customer } \\
\text { site. Ensure the transfer of best practices. Execution of Customer projects / } \\
\text { strategic initiative(s). Responsible for the education of all teams on the TPS } \\
\text { methodology. }\end{array}$ \\
\hline
\end{tabular}




\title{
APPENDIX II
}

Protocol for qualitative based survey

\section{WELCOME}

It is highly advisable to go through the following definitions to understand the research context. If you would like to have any questions about the study, please email at xyz@abc.edu or call at 123-456-7890.

Definitions: Paradoxes: "A paradox denotes a particularly challenging tension — contradictory, yet interrelated elements that exist simultaneously and persist over time. Managing paradox seeks "both/and" alternatives that may foster novelty, creativity, and long-term sustainability." (Lewis et al., 2014) Paradox Theory is defined as contradictions embedded within a statement (Murnighan \& Conlon, 1991), human emotions (Vince \& Broussine, 1996) or organizational practices (Lewis, 2000).

Please answer the following questions based on your understanding of the Paradoxes.

- What Paradoxical tensions can you think off in your day-to-day company/establishment ground operations?

- How do you deal with such Paradoxes? Do you prefer tackling them one at a time (i.e. trade off) or do you manage them simultaneously?

- Can you think of any specific Paradoxes that might have occurred during the current pandemic in your ground operations? (please list as many as you can)

- What Paradoxes might occur while a new method/technique or service (such as COVID specific plan) is implemented in the ground operations? How do you deal with them?

\section{APPENDIX III}

\author{
Protocol for face-to-face interviews
}

\section{Interview Questions}

Following questions are to be answered in the post Covid-19 context in the 3PL operations

Questions are to be answered only if the paradoxes mentioned exist in firm's operations.

\section{Performing:}

i. How do you (or your company/organization) manage interacting with customers while also maintaining safe distance?

ii. How do you (or your company/organization) manage servicing critical customers volume (PPE, ventilators etc.) while also processing regular customers volume (e-commerce, regular mail etc.) simultaneously?

iii. How do you (or your company/organization) manage to save on delivery times while also dealing with increased driver absentees due to sickness? 
iv. How do you (or your company/organization) manage to efficiently service ever increasing volume in the hub while also eliminating the excess working hours?

v. How do you (or your company/organization) decide on spending money (on training, PPEs etc.) while also maintaining cost cutting?

vi. How do you (or your company/organization) manage to efficiently service ever increasing volume in the hub while also facing the shortage of skilled employees (or employees calling off)?

vii. How do you (or your company/organization) prioritize worker safety and also ensure timely delivery of critical packages?

\section{Learning:}

i. How do you (or your company/organization) manage learning newer methods while also keeping the older (more efficient) ones in practice?

\section{Performing-Belonging}

i. How do you (or your company/organization) manage satisfying performance metrics from different business units such as IT and Hub?

\section{Performing-Organizing}

i. How do you (or your company/organization) maintain social distance in hub and also ensure hub performance?

ii. How do you (or your company/organization) maintain social distance in hub and also efficiently service increase in volume?

Organizing

i. How do you (or your company/organization) ensure accountability while also allowing flexibility to employees?

ii. How do you (or your company/organization) manage between hiring more staff to process volume while also maintaining social distance in the hub?

iii. How do you (or your company/organization) manage between high work pace and sudden amendment in strategies?

\section{Learning-Organizing}

i. How are newer methods incorporated while still observing social distance within the Hubs? 


\section{APPENDIX IV}

Table A-2: First and second order codes from face-to-face interviews using NVivo-12

\begin{tabular}{|c|c|c|c|c|}
\hline Paradox & Second Order & First Order Codes & Illustrative Quotations & $\begin{array}{c}\text { No. of } \\
\text { excerpts }\end{array}$ \\
\hline \multirow{8}{*}{$\begin{array}{l}\text { Interact with } \\
\text { customers and } \\
\text { still keep } \\
\text { distance }\end{array}$} & \multirow{5}{*}{ a. Interaction Less Service } & i. No signatures required & $\begin{array}{l}\text { "not having to make that customer interaction in order to get } \\
\text { signatures and things of that nature" }\end{array}$ & 8 \\
\hline & & ii. Leave the package on the door & "..driver can leave the package on the door" & 4 \\
\hline & & $\begin{array}{l}\text { iii. Meeting customers or clients through } \\
\text { Zoom }\end{array}$ & "..I believe that we transitioned over zoom" & 2 \\
\hline & & iv. Using access points & "..we have increased the usage of is access points" & 1 \\
\hline & & v. Mobile phone app scheduler & $\begin{array}{l}\text { "Company quantum view app allows customers to schedule their } \\
\text { shipments so that they can try to get them at times that they } \\
\text { want". }\end{array}$ & 1 \\
\hline & \multirow{3}{*}{ b. Communication } & $\begin{array}{l}\text { i. Communicating the guidelines to the } \\
\text { employees }\end{array}$ & $\begin{array}{l}\text { "set parameters, social distance guidelines were passed down, } \\
\text { top down, there were protocols and guidelines for everybody" }\end{array}$ & 3 \\
\hline & & $\begin{array}{l}\text { ii. Communication with up-stream } \\
\text { retailers through IT }\end{array}$ & $\begin{array}{l}\text { "So pretty much all the communication had to be done virtually } \\
\text { whether, you know, zoom call, or phone call or email..." }\end{array}$ & 3 \\
\hline & & iii. Setting protocols & $\begin{array}{l}\text { "So we had to follow simple protocols so we can safely } \\
\text { communicate by keeping the six feet or even more distance, and } \\
\text { have a mask on" }\end{array}$ & 1 \\
\hline \multirow{6}{*}{$\begin{array}{c}\text { Regular } \\
\text { Customers and } \\
\text { Critical } \\
\text { Customers }\end{array}$} & \multirow{2}{*}{ a. Priority Packages } & i. Prioritize critical health care packages & $\begin{array}{l}\text { "So we made sure to prioritize all critical health care } \\
\text { packages." }\end{array}$ & 5 \\
\hline & & ii. Prioritize special delivery & $\begin{array}{l}\text { "So you have packages with different labels on them that give } \\
\text { them that higher priority." }\end{array}$ & 4 \\
\hline & \multirow[b]{2}{*}{ b. Additional Partners } & $\begin{array}{l}\text { i. Using third party partners to help } \\
\text { service }\end{array}$ & $\begin{array}{l}\text { "It goes through or last, or last mile department, whatever, it's } \\
\text { beyond that, then we utilize or other } 3 P L \text { partners to help us" }\end{array}$ & 1 \\
\hline & & ii. Pull in some different partners & $\begin{array}{l}\text { "I would say we definitely needed to pull in some different } \\
\text { partners to help us manage these high priority shipments } \\
\text { packages" }\end{array}$ & 1 \\
\hline & \multirow[b]{2}{*}{ c. Operational Plans } & i. Adding extra sorts & $\begin{array}{l}\text { "We put up additional sorts on certain days or weeks, but we } \\
\text { couldn't put up new buildings..." }\end{array}$ & 1 \\
\hline & & ii. Dedicated inbound/outbound bays & $\begin{array}{l}\text { "We have special bays, where we unload air ... drivers will } \\
\text { come back and then drop off their air versus the regular ground } \\
\text { packages." }\end{array}$ & 1 \\
\hline
\end{tabular}




\begin{tabular}{|c|c|c|c|c|}
\hline & \multirow[t]{2}{*}{ d. Increased Visibility } & i. Technology application & $\begin{array}{l}\text { "So there has been a lot of increased visibility on a lot of those } \\
\text { medical type shipments, especially PPE and even like vaccines } \\
\text { and stuff...." }\end{array}$ & 1 \\
\hline & & ii. Visibility mechanism & $\begin{array}{l}\text { "They have the mechanism where they can see exactly where the } \\
\text { package is throughout the network...." }\end{array}$ & 1 \\
\hline \multirow{8}{*}{$\begin{array}{l}\text { Saving } \\
\text { delivery times } \\
\text { and drivers } \\
\text { calling out }\end{array}$} & \multirow[t]{2}{*}{ a. Overtime to the drivers } & $\begin{array}{l}\text { i. Flexibility from top management to } \\
\text { give overtime }\end{array}$ & $\begin{array}{l}\text { "So what I mean to say is if in regular times or pre COVID era, if } \\
\text { a driver hits } 15 \text { hours of overtime, we had to give explanations to } \\
\text { all of our bosses ... we did not have to give those" }\end{array}$ & 3 \\
\hline & & ii. Giving extra rewards for overtime & $\begin{array}{l}\text { "giving incentives to these to these drivers, taking care of } \\
\text { families and stuff" }\end{array}$ & 1 \\
\hline & \multirow{2}{*}{ b. Outside help } & i. Hiring make shift delivery drivers & $\begin{array}{l}\text { "And then maybe they have a, let's say, a small car, where they } \\
\text { can also take maybe } 2025 \text { packages in there" }\end{array}$ & 3 \\
\hline & & ii. Hiring outside contractors & "hiring outside contractors, was definitely a big thing for us." & 3 \\
\hline & \multirow{2}{*}{$\begin{array}{l}\text { c. Modified Operational } \\
\text { Plans }\end{array}$} & i. Adding safety net in the plans & $\begin{array}{l}\text { "So the industrial engineers in our organization, added a lot of } \\
\text { safety net to the operations." }\end{array}$ & 2 \\
\hline & & ii. Plans incorporating new Normal & $\begin{array}{l}\text { "Now we know traffic, you only take two minutes, you only take, } \\
\text { let's say } 30 \text { seconds. So that's one hour that we can utilize to } \\
\text { deliver more packages." }\end{array}$ & 1 \\
\hline & \multirow{2}{*}{ d. Added Workload } & $\begin{array}{l}\text { i. Leveraging resources-Internal } \\
\text { Managers filling in }\end{array}$ & $\begin{array}{l}\text { "And then also utilizing, you know, our management team or } \\
\text { management staff to fill in if needed help." }\end{array}$ & 1 \\
\hline & & ii. Splitting up jobs & $\begin{array}{l}\text { "When you have people call out, you kind of have to split up } \\
\text { certain, you know, route with different drivers." }\end{array}$ & 1 \\
\hline \multirow{6}{*}{$\begin{array}{l}\text { Performing } \\
\text { efficiently and } \\
\text { eliminating } \\
\text { excess hours }\end{array}$} & \multirow[b]{2}{*}{ a. Network Optimization } & i. Balancing Volume & $\begin{array}{l}\text { "so by balancing volume, we were able to not have to run longer } \\
\text { than we usually work during these peak seasons" }\end{array}$ & 2 \\
\hline & & $\begin{array}{l}\text { ii. Excess volumes go through other } \\
\text { buildings }\end{array}$ & $\begin{array}{l}\text { "being able to identify which shipments which customers, you } \\
\text { know, go better through different facilities, you know, could help } \\
\text { your throughput just by processing the right work and the right } \\
\text { building" }\end{array}$ & 1 \\
\hline & \multirow{2}{*}{ b. Customer Responsibility } & i. Holding customers accountable & $\begin{array}{l}\text { "we got to hold the customers more accountable for their } \\
\text { forecasts, and the timing of their loads" }\end{array}$ & 4 \\
\hline & & ii. Sitting access customer volume & "Start picking up on customers based on the allowance..." & 1 \\
\hline & \multirow{2}{*}{$\begin{array}{l}\text { c. Modifying Operational } \\
\text { Methods }\end{array}$} & i. No double-ups in trailers & $\begin{array}{l}\text { "We were not allowed to put two individuals in the same trailer. } \\
\text { So you would only have single individuals unloading." }\end{array}$ & 1 \\
\hline & & ii. Utilizing hub space & $\begin{array}{l}\text { "Optimizing our current processes and utilizing the space that } \\
\text { we have,...." }\end{array}$ & 1 \\
\hline
\end{tabular}




\begin{tabular}{|c|c|c|c|c|}
\hline \multirow{4}{*}{$\begin{array}{l}\text { Spending and } \\
\text { Saving Money }\end{array}$} & \multirow{4}{*}{$\begin{array}{l}\text { a. Safety Priority, Internal } \\
\text { Cost Cutting } \\
\text { Simultaneously }\end{array}$} & i. Identify mundane tasks & $\begin{array}{l}\text { "When it came to, like buying food, having food communally } \\
\text { during COVID is bad, in general, and we just we stopped doing } \\
\text { that". }\end{array}$ & 4 \\
\hline & & ii. Cut cost through low staffing & $\begin{array}{l}\text { As far as cost cutting, really, we just try to work the amount of } \\
\text { people we need. }\end{array}$ & 1 \\
\hline & & iii. Costs covered through revenue & $\begin{array}{l}\text { So while keeping everybody safe. What's the max volume that we } \\
\text { can service and make the money? So that was the main goal. }\end{array}$ & 1 \\
\hline & & iv. Not flying people out & $\begin{array}{l}\text { We stopped having meetings. So it's we saved on costs of flying } \\
\text { people out to buildings and risks. Workshops, we did all virtual. }\end{array}$ & 1 \\
\hline \multirow{8}{*}{$\begin{array}{l}\text { Prioritize } \\
\text { supply and } \\
\text { shortage of } \\
\text { employees }\end{array}$} & \multirow{4}{*}{ a. Training } & i. Coverage employees & $\begin{array}{l}\text { So we have coverage employees now, so that if one call is off, you } \\
\text { have somebody to replace them. }\end{array}$ & 3 \\
\hline & & ii. Cross-Training Employees & $\begin{array}{l}\text { we focus more on making sure that people we had were cross } \\
\text { train, so that people could do more jobs than they could before. }\end{array}$ & 4 \\
\hline & & iii. Deskilling the processes & $\begin{array}{l}\text { it's a studied position, you have to have some type of knowledge, } \\
\text { getting those positions to be deskilled }\end{array}$ & 3 \\
\hline & & iv. Efficient training of new employees & $\begin{array}{l}\text { "I'm really trying to streamline our training process, I'm putting } \\
\text { the right people in positions to train these people when they come } \\
\text { in, and get them up to speed as fast as possible" }\end{array}$ & 1 \\
\hline & \multirow{2}{*}{ b. Human Resource } & i. Added work hours & $\begin{array}{l}\text { "So I think it just resulted in the less people the longer hours } \\
\text { were can't really no way around it." }\end{array}$ & 4 \\
\hline & & ii. More staffing & $\begin{array}{l}\text { "So we kind of got to capitalize on being able to hire new people } \\
\text { that had previously lost their job." }\end{array}$ & 2 \\
\hline & \multirow{2}{*}{ c. Rolling over loads } & i. Customer volume cap & $\begin{array}{l}\text { "we just had to sit some inbound volume and then just process it } \\
\text { the following day and the customer was aware and knew the } \\
\text { circumstances," }\end{array}$ & 1 \\
\hline & & ii. Non-essential loads & $\begin{array}{l}\text { "we rolled non-essential loads during COVID, we could not } \\
\text { handle all the volume, we're very specific in which loads, we did } \\
\text { not process." }\end{array}$ & 1 \\
\hline \multirow{3}{*}{$\begin{array}{c}\text { Prioritize } \\
\text { worker safety } \\
\text { and delivery of } \\
\text { critical } \\
\text { packages }\end{array}$} & \multirow[t]{2}{*}{ a. Safety } & i. Safety Culture & $\begin{array}{l}\text { "So, we call it a culture of safety, you know, is a term that's used } \\
\text { a lot, if the first thing you hear when you walk in, and the last } \\
\text { thing you hear when you walk out is always safety" }\end{array}$ & 7 \\
\hline & & ii. Safety part of the training & $\begin{array}{l}\text { "Making sure safety is a big part of the training, and in that it's } \\
\text { integrated in learning how to do the job" }\end{array}$ & 2 \\
\hline & $\begin{array}{l}\text { b. New Operational } \\
\text { Methods }\end{array}$ & i. Methods in place & $\begin{array}{l}\text { "So in loads where we normally have two people working } \\
\text { together, we would have to make sure that if they both people had } \\
\text { to wear masks and make sure they had sufficient PPE" }\end{array}$ & 3 \\
\hline
\end{tabular}




\begin{tabular}{|c|c|c|c|c|}
\hline & & ii. Changed methods for employee & $\begin{array}{l}\text { "So we changed methods for employees to make sure that they } \\
\text { were able to socially distance while still working as efficiently as } \\
\text { possible" }\end{array}$ & 3 \\
\hline & \multirow{2}{*}{$\begin{array}{l}\text { c. Effective Checking in } \\
\text { the Hubs }\end{array}$} & i. Check through Technology & $\begin{array}{l}\text { "We need to install cameras have heating maps, and then all } \\
\text { sorts of structures inside the buildings to ensure social } \\
\text { distancing" }\end{array}$ & 2 \\
\hline & & ii. Keep a Check & $\begin{array}{l}\text { "As management team, on the floor, obviously, addressing any } \\
\text { behavior that we find unsafe, while also making sure that you } \\
\text { know, everybody's performing their duties at the requisite level" }\end{array}$ & 1 \\
\hline \multirow{7}{*}{$\begin{array}{l}\text { New methods } \\
\text { and old } \\
\text { methods }\end{array}$} & \multirow{3}{*}{ a. Communication } & i. Convincing the employees & $\begin{array}{l}\text { "So the biggest thing is obviously, getting the buy in from the } \\
\text { affected parties. convincing them that this change is, not only } \\
\text { going to be a better way in the long run, but it's going to help } \\
\text { them" }\end{array}$ & 4 \\
\hline & & ii. Ice Breaking before work & $\begin{array}{l}\text { "So showing up turning cameras on chit chatting, you know, } \\
\text { maybe for } 15 \text { minutes, speak up or something else other than } \\
\text { work" }\end{array}$ & 1 \\
\hline & & iii. Sell them the idea & $\begin{array}{l}\text { "so lot of people are afraid of change. So you kind of have to sell } \\
\text { them to it. Because people are used to their old ways, you know," }\end{array}$ & 1 \\
\hline & \multirow[t]{2}{*}{ b. Enforcement } & i. Enforcing SOPs through Supervisors & $\begin{array}{l}\text { "So we had to buy special equipment, and make sure to } \\
\text { supervisors over there that no driver or any worker doesn't } \\
\text { ignore that and just take off the mask" }\end{array}$ & 2 \\
\hline & & ii. Importance of safety in group tasks & $\begin{array}{l}\text { "We made sure that everyone understood how serious the } \\
\text { pandemic is, and how important is to distance" }\end{array}$ & 1 \\
\hline & \multirow[b]{2}{*}{ c. Modifying Methods } & i. Safety centric methods & $\begin{array}{l}\text { "we just modified the way they were performed to make sure they } \\
\text { were in a safe manner." }\end{array}$ & 1 \\
\hline & & ii. Happy balance & $\begin{array}{l}\text { "can I keep this method because this works? Well make it so that } \\
\text { it fits into the COVID model. To get that happy balance of this } \\
\text { keeps our employees safe, and also carries on that previous } \\
\text { method that is tried and tested and we know works." }\end{array}$ & 1 \\
\hline \multirow{4}{*}{$\begin{array}{l}\text { Performance } \\
\text { metrics } \\
\text { conflicts } \\
\text { between Ops } \\
\text { and other } \\
\text { Business Units }\end{array}$} & \multirow[b]{2}{*}{$\begin{array}{l}\text { a. Redefining the relations } \\
\text { between Business Units }\end{array}$} & i. Communication amongst BU's & $\begin{array}{l}\text { "Being able to decipher and explain that in a clear way. So that } \\
\text { everybody understands" }\end{array}$ & 3 \\
\hline & & ii. Redefining partnerships with BUs & $\begin{array}{l}\text { "Yeah, I would say, just making sure we, you know, we have we } \\
\text { have the right the right owners involved. And developing, y } \\
\text { partnership with our, our business units". }\end{array}$ & 4 \\
\hline & \multirow[t]{2}{*}{ b. Operations are the key } & i. Operations are the priority & $\begin{array}{l}\text { "everything is a support function to make sure that operations is } \\
\text { able to hit those numbers". }\end{array}$ & 2 \\
\hline & & ii. Production is critical & "I mean, production is always a major element" & 1 \\
\hline
\end{tabular}




\begin{tabular}{|c|c|c|c|c|}
\hline \multirow{6}{*}{$\begin{array}{l}\text { Social Distance } \\
\quad \text { and } \\
\text { Performance }\end{array}$} & \multirow{2}{*}{ a. Follow Protocols } & i. Communicating the guidelines & $\begin{array}{l}\text { "As far as managing performance with the protocols, you got to } \\
\text { make sure you have the right people in the right areas." }\end{array}$ & 3 \\
\hline & & ii. Strictly follow rules & $\begin{array}{l}\text { "Yeah, so it's tough. Um, so obviously, you know, you got to } \\
\text { follow the protocols as their pants down". }\end{array}$ & 2 \\
\hline & \multirow{2}{*}{$\begin{array}{l}\text { b. Using technology to } \\
\text { enforce protocols }\end{array}$} & i. Purchasing heating cameras & $\begin{array}{l}\text { "So it's, it's we have a heating cameras, , when t two people are } \\
\text { just getting closer, and alarm goes off," }\end{array}$ & 1 \\
\hline & & ii. Announcement & $\begin{array}{l}\text { "So we had to buy one of those mic thingies, so we're not } \\
\text { screaming on top of our lungs." }\end{array}$ & 1 \\
\hline & \multirow[b]{2}{*}{ c. Modifying Methods } & i. Loading/unloading methods & "not having not throwing multiple bodies into trailers," & 4 \\
\hline & & ii. Hub methods & $\begin{array}{l}\text { "Modified teamwork methods to make sure that we didn't have } \\
\text { people close together, but they were still able to help each other } \\
\text { out." }\end{array}$ & 2 \\
\hline \multirow{6}{*}{$\begin{array}{l}\text { Social distance } \\
\text { and increase in } \\
\quad \text { volume }\end{array}$} & \multirow{2}{*}{$\begin{array}{l}\text { a. Volume processed } \\
\text { externally }\end{array}$} & i. Using underutilized Hubs & $\begin{array}{l}\text { "Maybe some underutilized facilities that we weren't using a } \\
\text { certain type of way" }\end{array}$ & 4 \\
\hline & & ii. Outsourcing the volume & $\begin{array}{l}\text { "So yes, maybe you need, maybe you need to outsource that } \\
\text { volume" }\end{array}$ & 1 \\
\hline & \multirow[b]{2}{*}{ b. Increased sort times } & i. Increased sort band & $\begin{array}{l}\text { "So, you know, increased sorts bands, we would be operating } \\
\text { additional " }\end{array}$ & 3 \\
\hline & & ii. Longer sorts & $\begin{array}{l}\text { "Well, that mainly just having a longer sort. So extending the } \\
\text { operation, the volume is going to increase, you don't want to } \\
\text { overflow, flood the building with people." }\end{array}$ & 1 \\
\hline & \multirow[t]{2}{*}{ c. Customer Responsibility } & i. Customer volume limit & $\begin{array}{l}\text { "So I guess that's where the kind of like you saw on the news } \\
\text { during peak form where we're limiting customers, like giving } \\
\text { them an allocation." }\end{array}$ & 2 \\
\hline & & ii. Control origin capacity & $\begin{array}{l}\text { "But from a management perspective, we have to control the } \\
\text { origin capacity...." }\end{array}$ & 1 \\
\hline \multirow{6}{*}{$\begin{array}{l}\text { Accountability } \\
\text { and flexibility }\end{array}$} & \multirow{2}{*}{$\begin{array}{l}\text { a. Flexibility based on } \\
\text { Documents }\end{array}$} & i. Doctors notes & $\begin{array}{l}\text { "making sure that they have actual, like doctor's notes or test } \\
\text { results are like something that's backed up with the reasoning" }\end{array}$ & 4 \\
\hline & & ii. Arrival documentation & $\begin{array}{l}\text { "So if you needed to be out of work, because you had a family } \\
\text { member, you needed documentation on arrival" }\end{array}$ & 1 \\
\hline & \multirow[b]{2}{*}{ b. Employee based } & i. Types of employees & "So we had to separate with those particular employees" & 1 \\
\hline & & ii. Trust with employees & $\begin{array}{l}\text { "we kind of have to hold them more accountable than an } \\
\text { employee who we know we can trust" }\end{array}$ & 3 \\
\hline & \multirow[b]{2}{*}{ c. Communication } & i. Making HR aware & $\begin{array}{l}\text { "But if you don't communicate that we're going to discipline like } \\
\text { we would have an employee that's just not showing up to work." }\end{array}$ & 1 \\
\hline & & ii. Communication with management & $\begin{array}{l}\text { "But, you know, there's just constant communication with } \\
\text { management, and the employees to, know, see exactly what they } \\
\text { need and what they're going through." }\end{array}$ & 1 \\
\hline
\end{tabular}




\begin{tabular}{|c|c|c|c|c|}
\hline & & i. Special reporting procedure & $\begin{array}{l}\text { "So they just have to follow the proper process, so if they feel } \\
\text { sick, there is a two week quarantine process" }\end{array}$ & 1 \\
\hline & d. Special Covid Protocols & ii. Paid off time & $\begin{array}{l}\text { "if you got no if you if your COVID, positive, you know, you have } \\
10, \text { or } 14 \text { days, paid off" }\end{array}$ & 1 \\
\hline \multirow{7}{*}{$\begin{array}{c}\text { Maintain } \\
\text { distance in } \\
\text { hubs and more } \\
\text { hiring }\end{array}$} & \multirow{3}{*}{ a. Human Resource } & i. Capping the staff & $\begin{array}{l}\text { So we know that this is a certain number of people we need, this } \\
\text { area can only have this many people this area. }\end{array}$ & 2 \\
\hline & & ii. Hit the staffing number & $\begin{array}{l}\text { So we do have a staffing number that we get to, and we make } \\
\text { sure that we do hit the staffing number or get as close to it as } \\
\text { possible }\end{array}$ & 1 \\
\hline & & iii. Staffing assignments & $\begin{array}{l}\text { "We looked at each position and saw what how many people we } \\
\text { would be able to have in each area, while still maintaining social } \\
\text { distancing" }\end{array}$ & 2 \\
\hline & \multirow[b]{2}{*}{ b. Leveraging hub network } & i. Leveraging other hubs & "Maybe leveraging some different facilities. " & 1 \\
\hline & & ii. Access volume diversion & $\begin{array}{l}\text { "We can only handle this much. If we can't, if we go over this } \\
\text { mountain, other building needs to take this more." }\end{array}$ & 2 \\
\hline & \multirow{2}{*}{ c. Training } & i. Loading/Unloading training & $\begin{array}{l}\text { "So instead of having three person per trailers, we'll give one } \\
\text { person for every trailer that we can handle increase volume" }\end{array}$ & 1 \\
\hline & & ii. Distant learning & $\begin{array}{l}\text { "I would try to make sure that the demonstrations you know, for } \\
\text { employees were kept at a reasonable distance as possible, right." }\end{array}$ & 1 \\
\hline \multirow{6}{*}{$\begin{array}{l}\text { High work pace } \\
\text { and sudden } \\
\text { change in } \\
\text { strategy }\end{array}$} & \multirow{2}{*}{ a. Communication } & i. Communicating change & $\begin{array}{l}\text { "So I would say, again, communication is the biggest part, understanding } \\
\text { what's changing what impact it's going to have on any level of operation" }\end{array}$ & 3 \\
\hline & & ii. Clear communication & $\begin{array}{l}\text { "So clear communication with the people that work with you directly was } \\
\text { one and only proven strategy that worked for us." }\end{array}$ & 2 \\
\hline & \multirow{2}{*}{ b. Role of manager } & i. Know your team & $\begin{array}{l}\text { "Especially if it's critical, who's going to who, who we're going to call to } \\
\text { ensure that it gets done the right way" }\end{array}$ & 2 \\
\hline & & ii. Managerial experience & $\begin{array}{l}\text { "So that's where experience is huge. They kind of see things and can tell you } \\
\text { how it's going to play out." }\end{array}$ & 1 \\
\hline & \multirow{2}{*}{ c. Leverage resources } & i. Help from outside resources & $\begin{array}{l}\text { "And then I would say, definitely getting the support of some outside } \\
\text { resources to help manage through that change." }\end{array}$ & 1 \\
\hline & & ii. Providing resources & $\begin{array}{l}\text { "So let's start giving people equipment that they need to start feeling, you } \\
\text { know, at home", }\end{array}$ & 1 \\
\hline \multirow{2}{*}{$\begin{array}{l}\text { New methods } \\
\text { and social } \\
\text { distancing }\end{array}$} & \multirow{2}{*}{ a. Training } & i. Prolong training with few participants & $\begin{array}{l}\text { "But at the same time, we were trying to get those trainings done with three } \\
\text { people in the conference room and not } 15 \text {. So it took five days longer." }\end{array}$ & 3 \\
\hline & & ii. Quick tips & $\begin{array}{l}\text { "By just giving them certain tips, the most important ones and not do the } \\
\text { actual training, because doing the training in the conference room was not } \\
\text { an option". }\end{array}$ & 2 \\
\hline
\end{tabular}




\begin{tabular}{|l|l|l|}
\hline \multirow{2}{*}{ b. Safety } & i. Work around safety guidelines & $\begin{array}{l}\text { "everything we're normally used to doing is just now have to work around } \\
\text { these, you know, the mask and social distancing }\end{array}$ \\
\cline { 3 - 4 } & ii. Safety is priority & "The priority is always going to be employee safety." \\
\hline
\end{tabular}

